\title{
Silla turca vacía primaria: clínica, fisiopatología y tratamiento
}

\author{
J. González-Tortosa
}

Servicio Regional de Neurocirugía. Hospital Universitario Virgen de la Arrixaca. Murcia.

\section{Resumen}

En este artículo se revisa el concepto, clínica, fisiopatología y manejo de la silla turca vacía primaria y los distintos problemas que plantea, a la luz de la bibliografía que se ha considerado más relevante sobre el tema.

PALABRAS CLAVE: Silla turca vacía primaria. Síntomas. Diagnóstico. Etiología. Fisiopatología. Tratamiento.

Primary empty sella: symptoms, physiopathology, diagnosis and treatement

\section{Summary}

Bibliographical review on the primary empty sella: concept, symptomatology, diagnosis, physiopathology and management.

KEY WORDS: Primary empty sella. Symptoms. Diagnosis. Etiology. Physiopathology. Treatment.

\section{Concepto}

Cuando en las pruebas radiológicas de imagen se encuentra una invaginación de los espacios subaracnoideos hacia el interior de la silla turca, rellenándose ésta de lcr, de manera total o parcial, se habla de Silla Turca Vacía (STV). Este concepto implica una comunicación libre entre el líquido intraselar y el de la cisterna supraselar ${ }^{55}$.

La silla turca se encuentra normalmente ocupada en su totalidad por la hipófisis y el diafragma separa a la glándula de la cisterna supraselar. Este diafragma tiene un pequeño orificio por el que pasa el tallo hipofisario con sus vasos porta y las arterias de la trabécula ${ }^{107}$, normalmente situadas en ambos lados de su cara anterior. También suele haber unos repliegues subaracnoideos alrededor del tallo, que se insinúan hacia el interior de la silla turca por debajo del

Recibido: 3-05-08. Aceptado: 28-10-08 diafragma sellar, entre éste y la glándula.

Sin embargo, este orificio diafragmático puede estar ampliado y, en un $20 \%$ de las personas, se encuentra casi ausente $^{16}$, dejando de servir de barrera entre los espacios subaracnoideos de la base de cráneo y el contenido de la silla turca. En estos casos, si la glándula no ocupa todo el volumen sellar, el líquido cefalorraquídeo se introduce en su interior, en ocasiones ocupando todo el espacio de la fosa, dando la impresión de estar "vacía" en las pruebas de imagen, aunque siempre existe un resto glandular que, incluso en los casos extremos, tapiza su fondo.

\section{Silla turca vacía primaria y secundaria.}

Hay que distinguir dos tipos de silla vacía. Una originada de un proceso patológico, que puede ser o no de índole tumoral, aunque en la mayoría de los casos se trata de un adenoma que después sufre una involución, bien espontánea (apoplejía) o bien como consecuencia de su tratamiento (Fig. 1 y 2).

La consecuencia es que la cisterna aracnoidea de la base de cráneo se introduce en un espacio que ha quedado vacío dentro de la silla turca, aprovechando la dilatación del orificio diafragmático o la ausencia del diafragma de la silla. A estos casos se le denomina "Silla Turca Vacía Secundaria" (STVS).

El segundo tipo de silla vacía es aquel en el que no ha existido ningún proceso patológico previo, al menos conocido. Se le denomina "Silla Turca Vacía Primaria" (STVP) y tanto su patogenia como su repercusión clínico-quirúrgica, al no estar totalmente aclaradas, son objeto de debate y sobre ellas se centrará la revisión bibliográfica de este artículo.

Abreviaturas. CI: cisternografía isotópica. HG: hormona de crecimiento. HI: hipertensión intracraneal. HIA: hipertensión intracraneal aguda. HICI: hipertensión intracraneal crónica idiopática. lcr: líquido cefalorraquídeo. PIC: presión intracraneal. RM: resonancia nuclear magnética. RMC: RMcisternografía. STV: silla turca vacía. STVP: silla turca vacía primaria. STVPS: silla turca vacía primaria sintomática. STVS: silla turca vacía secundaria. TAC: tomografía axial computarizada. TACAR: TAC de alta resolución. TACC: TAC-cisternografía. 

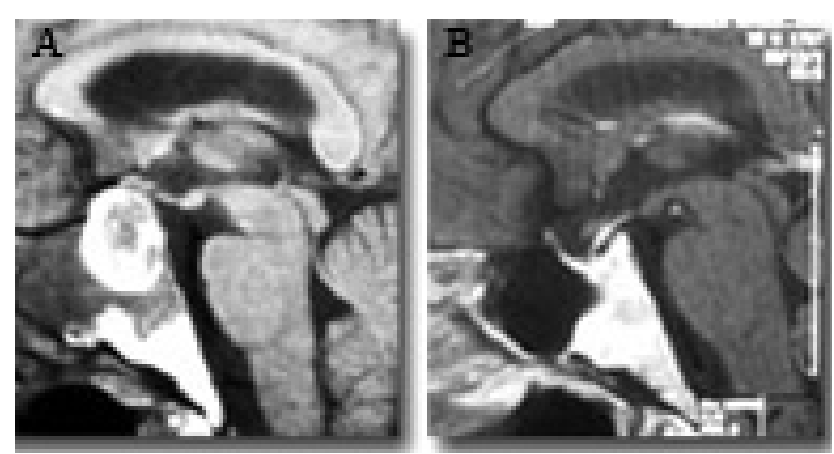

Figura 1. A: RM sagital de una apoplejía de un adenoma de hipófisis. B: RM del mismo paciente un año después: silla turca vacía, tras la resolución espontánea de la apoplejía.

\section{Silla turca vacía primaria}

\section{Epidemiología y manifestaciones clínicas}

La tabla 1 resume las características clínicas de la STVP. Generalmente son pacientes entre la cuarta y quinta décadas de la vida, con predominio del sexo femenino (5: 1), y con una alta incidencia de obesidad. La hipertensión arterial afecta a un 23\% de los casos en la serie de Bece$\mathrm{jac}^{8}$, y a un 59\% en la de Biaconcini ${ }^{9}$. Algunas de estas mujeres son multiparas $(16,6 \%)^{30}$.

La cefalea es el síntoma más frecuente en la mayoría de las series (40,3-88\%).

El zumbido pulsátil de oídos es un síntoma presente

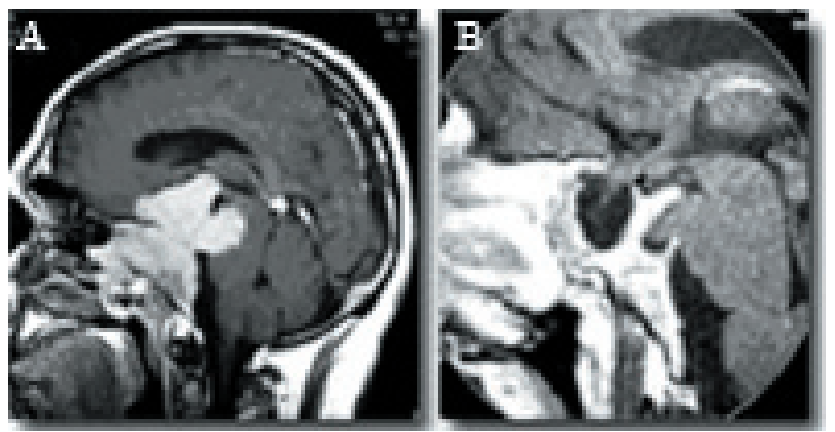

Figura 2. RM de un prolactinoma. A. Antes de iniciar tratamiento farmacológico. B. RM del mismo paciente, tras el tratamiento con dopaminérgicos: silla turca vacía secundaria.

en la mayoría de los casos de hipertensión intracraneal idiopática, por lo que orienta hacía el diagnóstico en los pacientes con STVP que lo padecen ${ }^{87}$.

Las alteraciones visuales (15-45\%) consisten, por lo general, en disminución de agudeza visual o visión borrosa $^{65}$; Spaziante y col. ${ }^{90}$, encontraron en 32 casos una disminución concéntrica de campos visuales $(6,4 \%)$, hemianopsia bitemporal $(6,4 \%)$ y una reducción de campos con aumento de la mancha ciega $(3,1 \%)$, sin presentar alteraciones campimétricas la mayoría de los pacientes $(84,4 \%)$. Se han publicado casos aislados con alteraciones campimétricas de morfología variable ${ }^{14,23,44,85}$.

Tabla 1

Alteraciones clínicas en STV primaria en los adultos

\begin{tabular}{|c|c|c|c|c|}
\hline & De Marinis ${ }^{25}$ & Maira $^{65}$ & Becejac $^{8}$ & Biaconcini $^{9}$ \\
\hline Mujeres & $80,2 \%$ & $88 \%$ & 75,8 & \\
\hline Edad promedio & $51,8 \mathrm{a}$ & $50 \mathrm{a}$ & $?$ & \\
\hline Obesidad & $14 \%(2 *)$ & $52 \%$ & $74,4 \%$ & $66,1 \%$ \\
\hline Cefalea & $40,3 \%(*)$ & $88 \%$ & $85,7 \%$ & $73,2 \%$ \\
\hline Alt. visuales & $15 \%$ & $45 \%\left(3^{*}\right)$ & $26,2 \%$ & $?$ \\
\hline Papiledema & $9,8 \%$ & $25 \%$ & $?$ & $?$ \\
\hline Alt. menstruales & $42 \%$ & $40 \%$ & $?$ & $?$ \\
\hline Disf. sexual (ठ) & $?$ & $53 \%$ & $?$ & $?$ \\
\hline Galactorrea & $2,8 \%$ & $20 \%$ & $?$ & $?$ \\
\hline Alt. mentales & & & $?$ & $80,2 \%(4 *)$ \\
\hline Rinorrea & $6,5 \%$ & $24 \%$ & - & $?$ \\
\hline HA & - & $?$ & $23,8 \%$ & $59,1 \%$ \\
\hline
\end{tabular}

*Como $1^{\text {er }}$ motivo de consulta. $2 *$ Obesidad mórbida $3 *$ Visión borrosa. Alt. campimétricas. Amaurosis 4* Ansiedad, alteaciónes distímicas o del comportamiento. 
La inmensa mayoría de los enfermos no presentan papiledema.

Solo una serie ${ }^{9}$ ha prestado atención a las alteraciones mentales $\mathrm{y}$, de manera sorprendente, son muy frecuentes $(80,2 \%)$. Se trata, sobre todo, de cuadros de ansiedad y alteración distímica o del comportamiento.

La sintomatología endocrinológica consiste, fundamentalmente, en alteraciones menstruales en las mujeres pre-menopáusicas (40\%), con menos de una quinta parte de pacientes con galactorrea (2,8-20\%), o disfunción sexual en los hombres (53\%).

\section{Fístula de líquido cefalorraquídeo}

El 2.8-24\% de los pacientes presentan rinorrea espontánea que, una vez que se inicia, al contrario de las fístulas postraumáticas, no suele curar de manera espontánea, aunque sí cursar con periodos de remisión parcial o total. Es frecuente que comience tras un golpe de tos o estornudo, por lo que suele ser considerada como una rinitis alérgica, en especial si la rinorrea es escasa y autolimitada. De hecho, no es raro que la padezcan durante mucho tiempo, incluso años. A veces, cuando es profusa y mantenida, es cuando suele ser motivo de consulta al médico.

Es típico que el paciente presente cefalea matutina que, tras iniciar la descarga del líquido por la nariz, desaparece o mejora. También es característico que aumente la egresión cuando el paciente se inclina hacia delante, lo que se ha atribuido al vaciamiento del líquido acumulado en el seno esfenoidal cuando, por la inclinación de la cabeza, alcanza las aberturas del seno esfenoidal, situadas en su pared anterior.

El 26\% de los pacientes con rinorrea, padecen meningitis ${ }^{37}$, siendo a veces el síntoma inicial. El riesgo de padecerla es de un $10 \%$ anual $^{29}$, por lo que es imperativo su tratamiento quirúrgico. Algunos de ellos sufren varios episodios, que deben de hacer sospechar siempre la posibilidad de una fístula de lcr oculta.

\section{Alteraciones endocrinológicas}

La tabla 2 resume las alteraciones hormonales publicadas en algunas series.

Los resultados varían en razón al método de valoración utilizado y a la práctica de test funcionales. En general, es habitual el déficit aislado, aunque también se producen combinaciones de ellos. El más frecuente es el déficit de hormona de crecimiento (15-61\%). El panhipopituitarismo es raro $(4,2-10,4 \%)$, así como la presencia de diabetes insípida (2,8\%). La hiperprolactinemia afecta alrededor del $10 \%$ de los pacientes ${ }^{1,12,17,18,25}$.

En general, la incidencia global de alteraciones hormonales, cuando se hacen pruebas funcionales, es alta, con más del $50 \%$ de los casos en la mayoría de las series.

Las determinaciones basales de las hormonas, no siempre son indicativas de un buen funcionamiento de las mismas $^{1}$. En consecuencia, hay que realizar test funcionales cuando se sospecha su déficit. Esto es especialmente relevante en el caso de que el cortisol se encuentre en la mitad inferior del rango considerado como normal y exista sintomatología clínica sugerente de insuficiencia suprarrenal.

El déficit de hormona de crecimiento se traduce en un déficit de su brazo efector, la $\operatorname{IgF} 1$, pero para concretarlo es necesario confirmar la ausencia de respuesta adecuada de la HG ante una prueba de estímulo, generalmente la hipoglucemia insulínica ${ }^{21}$. Diagnosticarlo es importante en los adultos porque, en personas de menos de 60 años, existe indicación de tratamiento sustitutivo que contrarreste el deterioro de la calidad de vida, la tendencia al depósito de grasa a nivel visceral, la alteración en el perfil lipídico y los posibles efectos perjudiciales para la arteriosclerosis

Tabla 2

Alteraciones endocrinológicas en STV primaria en los adultos

\begin{tabular}{|l|c|c|c|c|c|}
\hline & De Marinis $^{\mathbf{2 5}}$ & Becejar $^{8}$ & ${ }^{*}$ Gasperi $^{\mathbf{3 8}}$ & Cannavo $^{\mathbf{1 8}}$ & Biaconcini $^{\mathbf{9}}$ \\
\hline Hiperprolactinemia & $10,3 \%$ & $7,14 \%$ & $?$ & $11,6 \%$ & $14 \%$ \\
\hline Déficit de HG & $22,2 \%$ & $42,8 \%$ & $61 \%$ & $34,8 \%$ & $15,4 \%$ \\
\hline Déficit de ACTH & $21,4 \%$ & $21,4 \%$ & $?$ & $11,6 \%$ & $?$ \\
\hline Déficit de GNH & $?$ & $9,5 \%$ & $?$ & $25,3 \%$ & $7 \%$ \\
\hline Déficit de TSH & $?$ & $2,3 \%$ & $?$ & $4,6 \%$ & $?$ \\
\hline Diabetes insípida & - & - & $?$ & - & $2,8 \%$ \\
\hline Panhipopituitarismo & $4,2 \%$ & $9,5 \%$ & $?$ & $0 \%$ & $10,4 \%$ \\
\hline Incidencia global & $18,7 \%$ & $66,6 \%$ & $?$ & $53 \%$ & $50,7 \%$ \\
\hline
\end{tabular}

*Estudio centrado sólo en la GH 
y sus consecuencias a largo plazo. También para disminuir la osteoporosis y su repercusión en las fracturas de cadera. En los niños con retraso de crecimiento, es obvia su importancia.

La hiperprolactinemia interfiere con la función del eje gonadotrópico. Por tanto, sólo se puede valorar éste una vez que se haya normalizado la prolactina, mediante tratamiento dopaminérgico.

La presencia de restos glandulares, incluso en las sillas "totalmente" vacías, hace que en ellos se pueda generar las patologías usuales de la hipófisis, en especial microadenomas de PRL, HG o ACTH²,10,36,61,67,88,95,96.

\section{STVP en los niños}

La incidencia de la STVP en los niños se encuentra en el rango del $1,2 \%$ al $11.1 \%{ }^{34,76,98,111}$. Las escasas publicaciones que existen al respecto $4,17,22,89,98,106,111$, ponen de manifiesto que no suelen presentar el síndrome típico de STVP de los adultos ${ }^{111}$, ni una mayor prevalencia femenina.

Sin embargo, es frecuente que se asocie a otras patologías intracraneales, en especial hidrocefalia no tumoral, pseudotumor $^{98,22}$, quistes aracnoideos supraselares ${ }^{4}$, e incluso tumores de fosa posterior de larga evolución ${ }^{4}$. Es decir, cuadros de hipertensión intracraneal crónicos.

También es frecuente que se asocie a otras enfermedades congénitas, como la anemia de células falciformes cuando se asocia a déficit de HG $(100 \%$ de los casos de Soliman $\left.{ }^{89}\right)$ o al sindrome del carcinoma de células basales nevoides $\left(60 \%\right.$ en la serie de Takanashi $\left.{ }^{98}\right)$, así como a otras anomalías de la base de cráneo, como la displasia ósea del esfenoides. Es decir, la STV en niños no suele tener el carácter benigno propio de los adultos.

Apenas existe bibliografía específica sobre las alteraciones visuales en STV en niños. En la serie recogida por Costigan y $\mathrm{col}^{22}$, el $29,4 \%$ de 17 casos presentaba alteraciones de los campos visuales, sobre todo reducción del campo visual, por lo que probablemente esté relacionado con el cuadro de hipertensión intracraneal, más que una patología propia de la silla vacía, como la que se ha publicado en ocasiones en los adultos.

En la serie de 23 casos recogida de la literatura por Costigan $^{22}$, un $30 \%$ de niños con STV se presenta con alteraciones endocrinas, y un $17,3 \%$ con rinorrea.

Las alteraciones endocrinológicas mas frecuentes, son el déficit de la hormona de crecimiento y la disfunción de las gonadotropinas ${ }^{22}$, por lo que la STV se encuentra con frecuencia entre los niños con retraso del crecimiento $(70 \%$ en la serie de Soliman) y de la pubertad $(40 \%$ en la serie de Cacciari $^{17}$ ), aunque también se han descrito casos con pubertad precoz $(4,2 \%)^{17}$.

No es infrecuente que la STV en niños esté asociada a déficit hormonales múltiples $\left(17,5 \%\right.$ a $80 \%{ }^{89,111}$.

\section{Evolución de la STVP}

La STVP es una entidad habitualmente estable, aunque un $10,3 \%$ de los casos se agrava con el tiempo y un $16,3 \%$ mejora $^{25}$.

\section{Pruebas de imagen en la STVP}

\section{Rx simple de cráneo}

Las características de la STVP en la radiografía simple de cráneo ${ }^{90}$, fueron descritas por Kaufman en $1968^{55}$.

La silla turca puede tener una apariencia normal, en cuanto a tamaño y forma (9\%), pero es frecuente un moderado agrandamiento, aunque no suele pasar de los $22 \mathrm{~mm}$ de largo, adoptando una forma globular (36\%) (Fig. 3B) o cuadrangular $(23 \%)$. Con menos frecuencia tiene una morfología en "copa" (11\%) o en omega (4\%).

El dorso se comba hacia atrás y se afina, pero no suele desplazarse, como sucede en los tumores hipofisarios, excepto en casos raros (Fig. 3D). Las apófisis clinoides suelen permanecer bien marcadas.

El suelo, cóncavo, puede tener una apariencia doble en las proyecciones laterales, pero la parte más deprimida está más marcada que las partes laterales, más superficiales, al contrario de lo que habitualmente sucede en los tumores intraselares (Fig. 3C). En las imágenes en sentido antero-posterior aparece de grosor simétrico, sin adelgazamientos o erosiones unilaterales, como es frecuente en los adenomas.

La pared anterior también se remodela hacia delante, pero no así el tubérculo de la silla, el surco óptico, ni el plano esfenoidal (Fig. 3C y 3D).

En ocasiones existe una silla profunda, con su pared anterior y dorso más verticales (17\%) (Fig. 3C).

La desaparición de la porción superior del dorso de la silla, o la erosión de las apófisis clinoides posteriores, son signos conocidos de los tumores pituitarios, pero también de la hidrocefalia crónica, en la que el tercer ventrículo se encuentra agrandado, apoyando su suelo sobre el dorso de la silla. En los niños, en los que la asociación de la silla turca vacía con hidrocefalia crónica es frecuente, es un signo que hay que tener en cuenta.

La calcificación de los ligamentos interclinoideos o del diafragma de la silla turca, dan un aspecto de "puente" a la fosa sellar y es un signo frecuente en el carcinoma de células basales nevoides (síndrome de Gorlin), enfermedad hereditaria autosómica dominante en la que se existe, con frecuencia, una STVP.

En ocasiones pueden ser evidentes signos radiológicos de hipertensión intracraneal crónica. La calcificación bilaminar de la hoz cerebral es uno de los criterios mayores para el diagnóstico del carcinoma de células basales nervoides $^{31}$, con el que se asocia frecuentemente la STVP $^{98}$ 

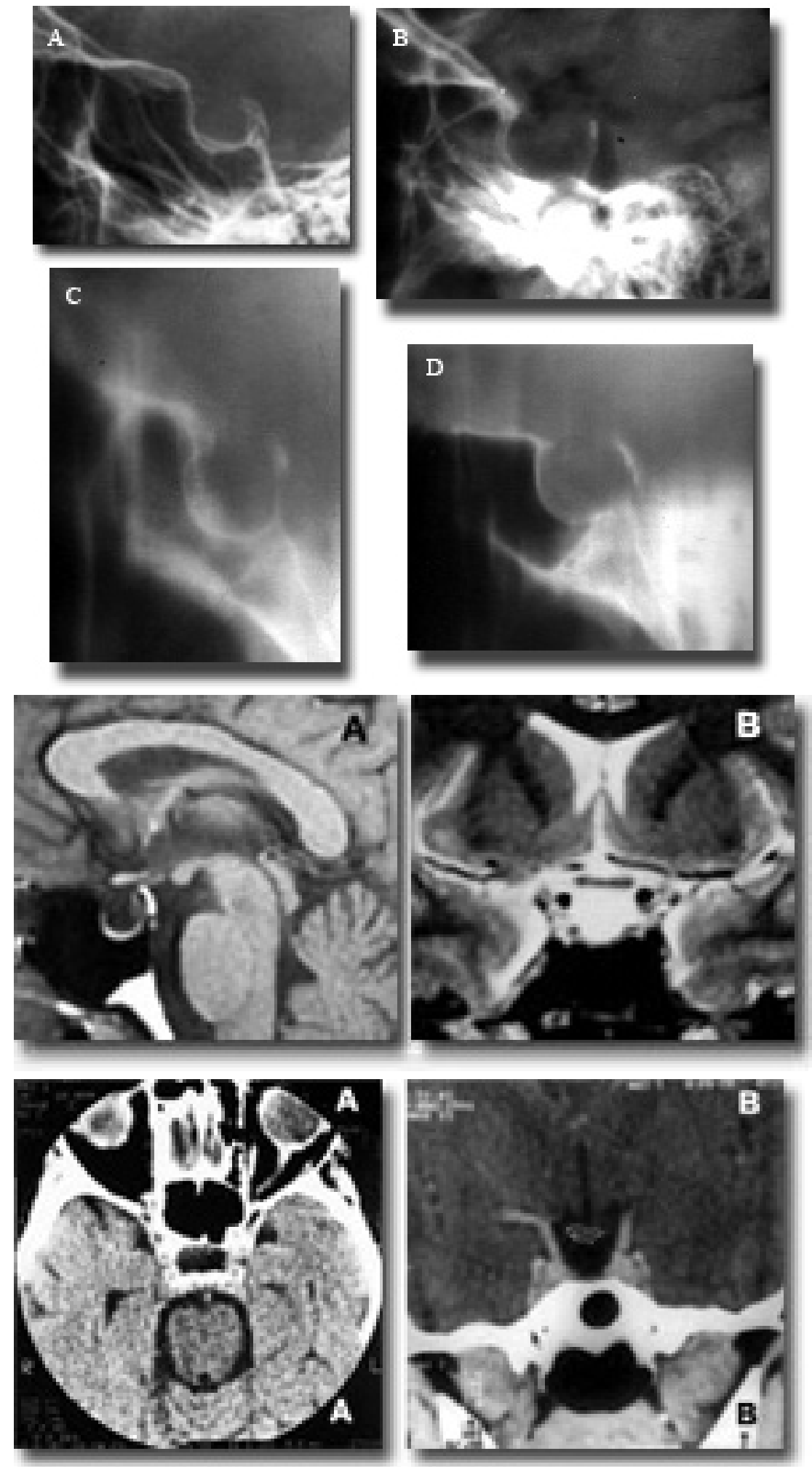

Figura 3. A: Rx simple lateral de cráneo: silla turca normal. B: STVP. Rx lateral de cráneo: silla agrandada y redonda. El dorso está adelgazado en su porción inferior, pero el extremo superior está bien definido. C: STVP. Tomografia medial de la silla turca: silla profunda, de paredes verticales y porción superior del dorso conservada. Imagen de doble suelo anterior, con la porción más deprimida bien marcada. D: STVP: erosión y desplazamiento, no habitual, de la porción inferior del dorso de la silla. Pero la parte superior permanece bien definida y la fosa mantiene una imagen "cerrada".

Figura 4. A: RM T1 sagital: el lcr de la cisterna de la base, se introduce en la silla turca. El tallo está acodado contra la porción superior del dorso de la silla. Existe una capa de adenohipófisis tapizando el fondo de su suelo. B: RM T2 coronal: el quiasma óptico, por encima de la emergencia de las arterias carótidas, tiene una morfología rectilínea. Las arterias cerebrales anteriores lo cruzan por encima.

Fig. 5. A: TC axial $+C$ : hipodensidad en la silla turca. B: TC coronal $+C$ : las arterias carótidas ascienden hacia las cisuras silvianas, cruzando por fuera la barra quiasmática.

\section{$T A C y R M$}

La STVP es fácilmente distinguible en el TAC y RM (Fig. 4, y 5). De manera típica se observa una silla turca ligeramente agrandada, con hipodensidad en su contenido en el TAC, o hipointensidad en las secuencias ponderadas en $\mathrm{T} 1$ e hiperintensidad en $\mathrm{T} 2$, en la $\mathrm{RM}$, que 

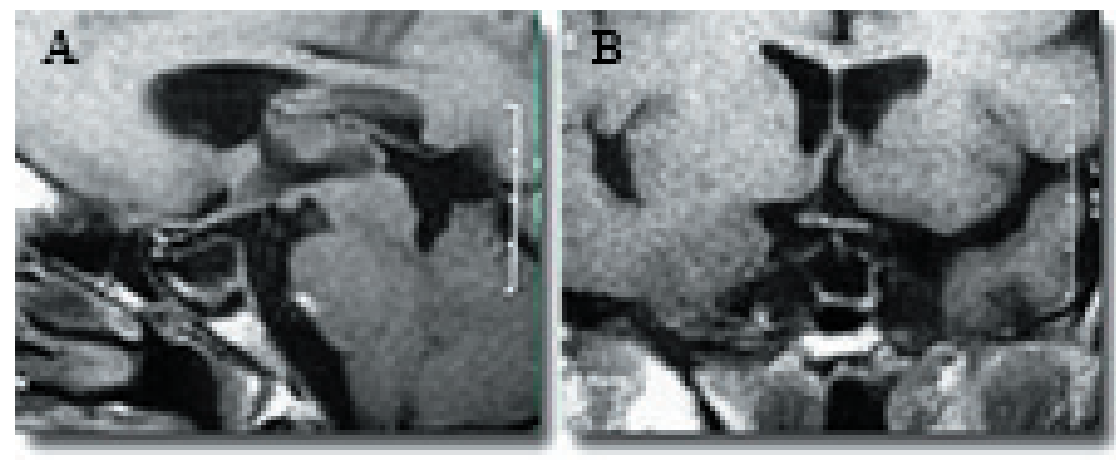

Figura 6. Lesión quística intraselar. la identificación de la delgada pared del quiste la diferencia de la STVP.
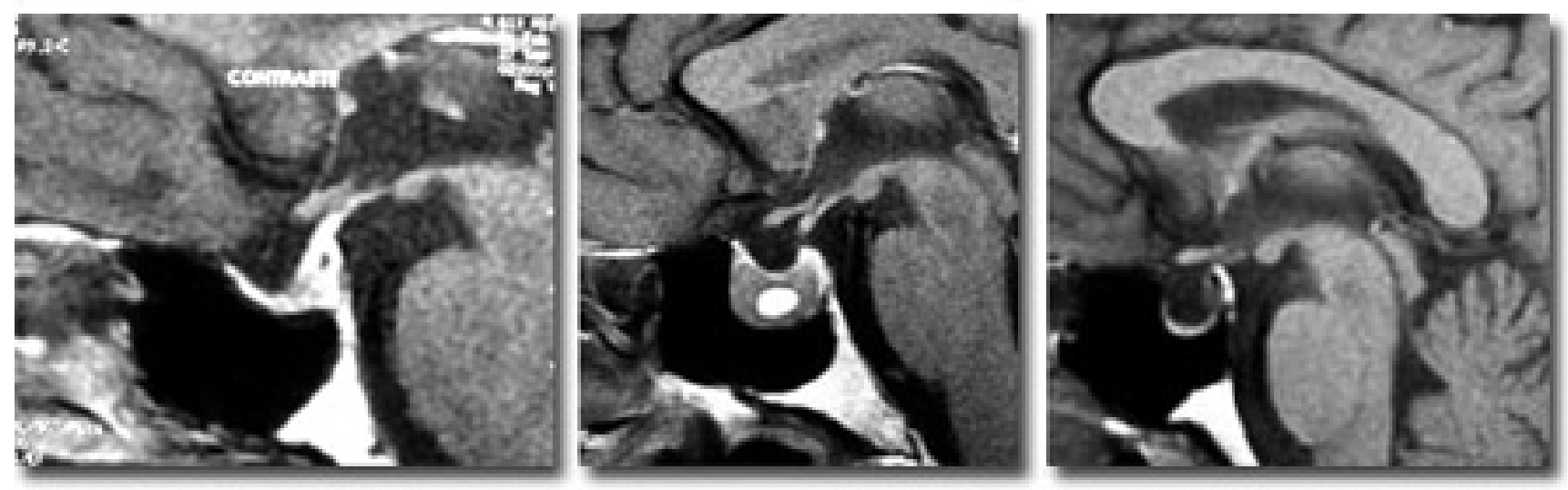

Figura 7. RM sagital: situación normal de las vías ópticas, en relación a la silla turca. En los tres casos, pese a la distinta posición relativa del tercer ventrículo respecto a la silla, el conjunto del quiasma óptico y porción anterior del suelo del tercer ventrículo, forma una línea recta con ligeras variaciones de la horizontal.

está en comunicación con los espacios subaracnoideos supraselares. El tallo hipofisario se encuentra desplazado hacia atrás en el $43 \%$ de los casos, acodándose sobre el borde superior del dorso de la fosa (Fig. 4A) El grado máximo de silla vacía solo se encuentra en el 2.5 $\%$ de los pacientes ${ }^{108}$.

El quiste aracnoideo de situación selar-supraselar, de tamaño moderado, puede plantear duda diagnóstica si la fina pared del quiste, no se delimita bien de la cisterna supraselar (Fig. 6).

La RM es mucho mejor para la identificación de los restos glandulares en el interior de la silla turca, o de la hernia de las vías ópticas y de la porción anterior del tercer ventrículo, por lo que es la exploración iconográfica de elección.

\section{Situación normal de las vías ópticas supraselares}

Dado que se han publicado casos en los que se atribuyen las alteraciones visuales a la hernia de las vías ópticas hacia el interior de la silla turca vacía, es pertinente recordar la situación y morfología normal de aquéllas en la $\mathrm{RM}^{54}$.

Desde los agujeros ópticos, los nervios ópticos se orientan hacia atrás para formar el quiasma óptico, por encima de la silla turca. Las cintillas ópticas emergen desde el quiasma para dirigirse, rodeando el mesencéfalo, hacia los tubérculos geniculados laterales.
En la RM sagital de cráneo y desde el canal óptico, los nervios ópticos, quiasma y porción anterior del suelo del tercer ventrículo, hasta los cuerpos mamilares, forman una línea recta que no se distorsiona con las variaciones normales de la posición del tercer ventrículo respecto a la silla turca (Fig. 7). Las cintillas ópticas, a veces, pueden ofrecer una ligera elevación, curva o angulada, en sus porciones más posteriores.

En el plano coronal, las apófisis clinoides aparecen hiperintensas con la hipointensidad de la carótida interna, a su entrada al cráneo, justo medial a ellas (Fig. 8 A). Los nervios ópticos se pueden identificar encima de las arterias. A partir de este punto, las carótidas sobrepasan por los lados a los nervios ópticos, dirigiéndose estos últimos, hacia la línea media, para formar el quiasma óptico, por encima de la fosa selar. En la secuencias de T1 y T2, se identifica el quiasma como una estructura horizontal recta, bien definida, sin ninguna angulación hacia abajo (Fig. 8 B).

El receso infundibular forma, con el del óptico, un ángulo agudo siempre por debajo de los $90^{\circ}$. Cuando está dilatado, hay que sospechar una alteración de la dinámica del lcr o de la presión intracraneal, como la que se produce en las dilataciones del tercer ventrículo por estenosis del acueducto de Silvio. 

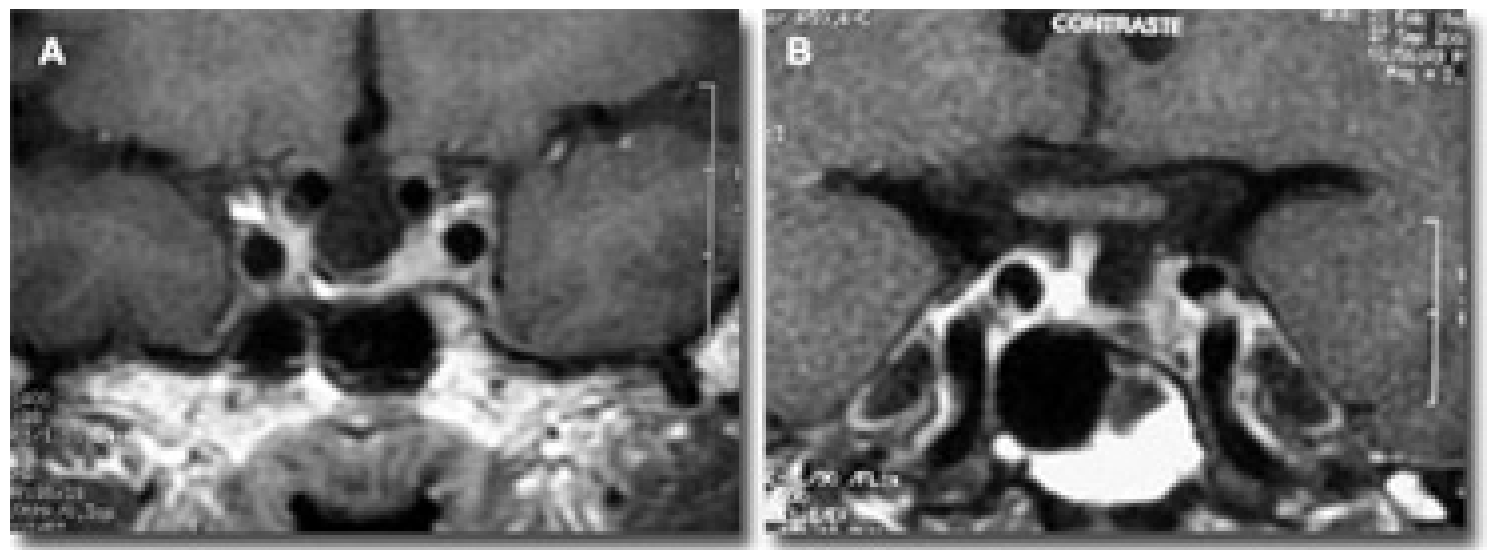

Figura 8. Situación normal de las vías ópticas, en el plano coronal. A: RM. T1 +C: por dentro de las apófisis clinoides, hiperintensas, se sitúan las carótidas a su entrada a la cavidad craneal. Por encima de ellas, aparecen los nervios ópticos isointensos. B: en un corte más posterior, la barra quiasmática se sitúa por encima de la silla turca vacía. Las arterias carótidas se separan de las vías ópticas y las arterias cerebrales anteriores, cruzando la cara superior del quiasma.
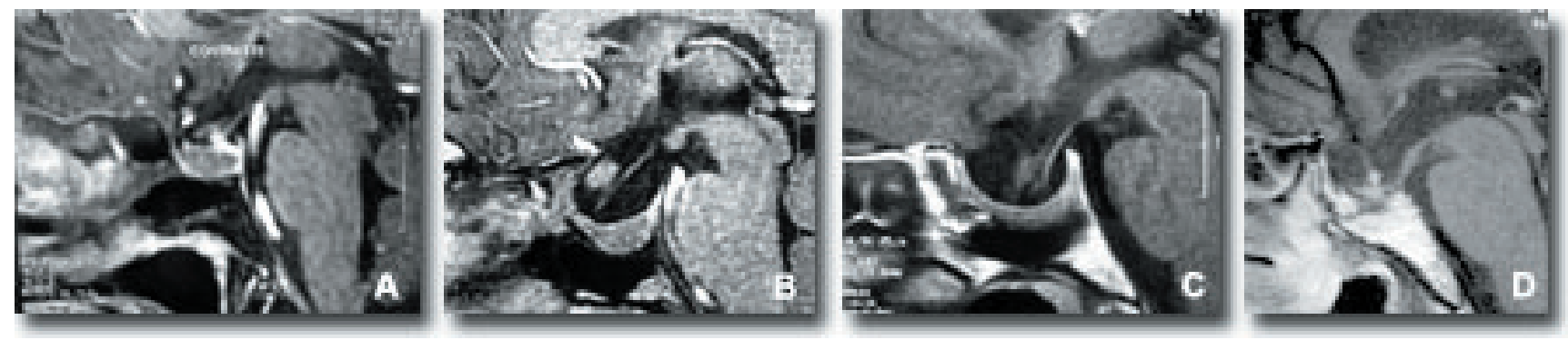

Figura 9. RM sagital en la STVS. Hernia de las vías ópticas, hacia el interior de la silla turca. A y B: el quiasma está ligeramente por debajo del tubérculo de la silla. La línea que forma con la porción anterior del suelo del tercer ventrículo, está quebrada. C y D: cuanto mas descienden las vías ópticas, más verticalidad adopta el suelo del tercer ventrículo. En todos los casos, son sillas "abiertas", con erosión de las porciones superiores del dorso sellar -excepto en C-, lo que evidencia la presencia de procesos tumorales previos.

Hernia de las vías visuales y porción anterior del tercer ventrículo, hacia el interior de la silla turca

La hernia de las vías ópticas hacia el interior de la silla turca vacía, es un hecho raro $(4,8 \%)$ en la STVP ${ }^{54}$. Los patrones de herniación ${ }^{54}$ están en función del grado de desplazamiento del quiasma y de la porción anterior del tercer ventrículo, a partir de los puntos de fijación de las vías ópticas.

Cuando las vías ópticas están descolgadas hacia el interior de la silla turca, se sitúan en un plano inferior al tubérculo de la silla y la línea recta que forma el quiasma con el suelo del tercer ventrículo se rompe, adoptando éste una orientación más vertical (Fig. 9). Los nervios ópticos se orientan también en dirección caudal, conforme se introducen en la silla turca. El ángulo del receso se acerca a los $90^{\circ}$.

En las proyecciones coronales, la distorsión que provoca el desplazamiento hace que el quiasma pierda su morfología rectilínea horizontal, deprimiéndose más en sus porciones mediales que en las laterales, debido al efecto sostén que realizan los nervios y cintillas ópticas (Fig. 10).

Signos de hipertensión intracraneal en los nervios ópticos

En el grupo de pacientes con pseudotumor cerebral, en los que la incidencia de STVP es tan frecuente, las presiones intracraneales son más altas que en el grupo de STVP en conjunto. En estos pacientes con hipertensión intracraneal idiopática típica, se han descrito alteraciones en la morfología de las vías ópticas intraorbitarias, en especial en los que presentan alteraciones visuales ${ }^{41}$. Fundamentalmente estas alteraciones consisten en una protrusión, de grado variable, de la cabeza del nervio óptico hacia el interior del globo ocular (70.5\%), muy relacionada con el grado de disfunción visual, y un aumento del grosor de los nervios ópticos a expensas de sus vainas $(70,5 \%)$. El aplanamiento de la esclerótica posterior en la RM, es el signo más sensible de elevación de la presión intracraneal $(80 \%)^{13}$. Gibby y $\mathrm{col}^{41}$, encontraron una silla vacía en el $94 \%$ de sus pacientes, 

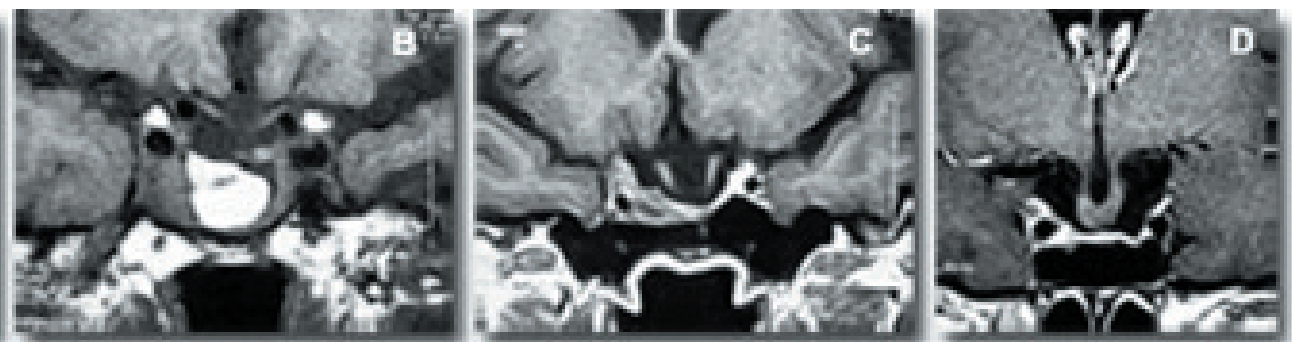

Figura 10. RM coronal en STVS. A, B y C: Los nervios ópticos inician el descenso hacia el fondo de la silla, desde su punto de fijación a nivel de los agujeros ópticos. D: El quiasma, dentro de la silla, distorsiona de manera típica su morfología horizontal.

de manera que la presencia de estas anomalías hace que el diagnóstico de pseudotumor cerebral sea muy probable, cuando se ha descartado otras causas de hipertensión intracraneal crónica.

\section{Diagnóstico de la rinorrea en la STVP}

La prevalencia de la fístula de lcr, en el grupo de pacientes con STVP, es del 2,8\% - 10\% $\%^{9,52}$. Sin embargo, si agrupamos los pacientes con fístulas espontáneas, la incidencia de STVP es del 63\% - 100\% de los $\operatorname{casos}^{78,82,84}$, considerando la silla vacía en sus diferentes grados.

Debido a que puede aparecer rinorrea en otros padecimientos frecuentes, como las rinitis alérgicas unilaterales, los quistes mucosos de los senos, quistes de retención o secreciones lagrimales, el primer paso es la confirmación de que el fluido nasal anormal es, efectivamente, líquido cefalorraquídeo.

Como el aspecto de la secreción nasal puede ser similar al lcr, en caso de secreciones lagrimales o rinitis alérgicas y, en el caso de mucoceles, tener un color pajizo equívoco, se recurre a la determinación de sustancias que normalmente no se encuentran en estos fluidos, pero sí lo están en el lcr. Esto implica que la fístula debe de estar activa en el momento de realizar la prueba.

\section{Marcadores de líquido cefalorraquídeo Glucosa}

En las décadas pasadas se ha utilizado como marcador, ya que no se encuentra en las secreciones nasales patológicas y sí en el lcr. La determinación de la glucosa en el líquido nasal se considera positiva cuando excede de $30 \mathrm{mg} / 100 \mathrm{ml}$. El problema es que tiene una sensibilidad de sólo $30 \%$, debido a la contaminación con sangre o lágrimas. Su especificidad es también sólo del $30 \%$, debido a la posibilidad de niveles bajos de glucosa en el $1 \mathrm{cr}^{19}$. En la actualidad, y dada la disponibilidad de otros marcadores más fiables, está cayendo en desuso ${ }^{3}$.

\section{Isótopos radioactivos}

A diferencia de los otros, es un marcador que se introduce en los espacios aracnoideos, mediante una punción lumbar. Se deja un tiempo para su difusión hacia la cavidad craneal ( 3 horas) y se recoge su posible actividad en la secreción nasal, mediante unas lentinas colocadas a propósito. Se aprovecha para obtener una imagen de la difusión intracraneal y su posible escape de ella, como después veremos. La cabeza del paciente se puede colocar en la posición en la que más líquido pierde, lo que es una ventaja.

El marcador que se utiliza es el 99mtc-DTPA (ácido dietilentriamino pentaacético marcado con tecnecio radioactivo) y es excelente para confirmar la fístula, con una sensibilidad del $100 \%$, incluso en los casos en los que no está activa ${ }^{37}$, aunque en esta circunstancia su efectividad desciende al $28 \%{ }^{28}$.

Hay que hacer una medición simultánea del marcador sangre, para determinar la proporción o índice del marcador entre las lentinas y la sangre. Por encima de 0,37 , se considera positivo.

Si se colocan lentinas en sitios específicos de la fosa nasal, como el receso esfeno-etmoidal, surco olfatorio y meato medio, puede mejorar la orientación sobre el sitio del escape. No obstante, pueden persistir las dudas, ya que una lentina positiva en el meato medio no puede diferenciar si el líquido viene del seno frontal o de las celdas etmoidales, puesto que ambos drenan hacia el mismo sitio.

La prueba tiene una alta sensibilidad en los casos de rinorrea activa. Cuando el resultado no sea positivo, se puede forzar la salida de líquido aumentando la presión intracraneal con infusión intratecal de lcr. artificial o suero salino, con lo que se acorta el tiempo del estudio. En estos casos, también se ha empleado el Indio- ${ }^{111}$ como marcador, ya que tiene una vida media más larga y permite hacer la prueba durante tres días, prolongando así la oportunidad de detectar la fístula.

La utilización de estos marcadores radioactivos implica radiación, incomodidad para el paciente y la posibilidad de complicaciones inherentes a un método invasivo. 


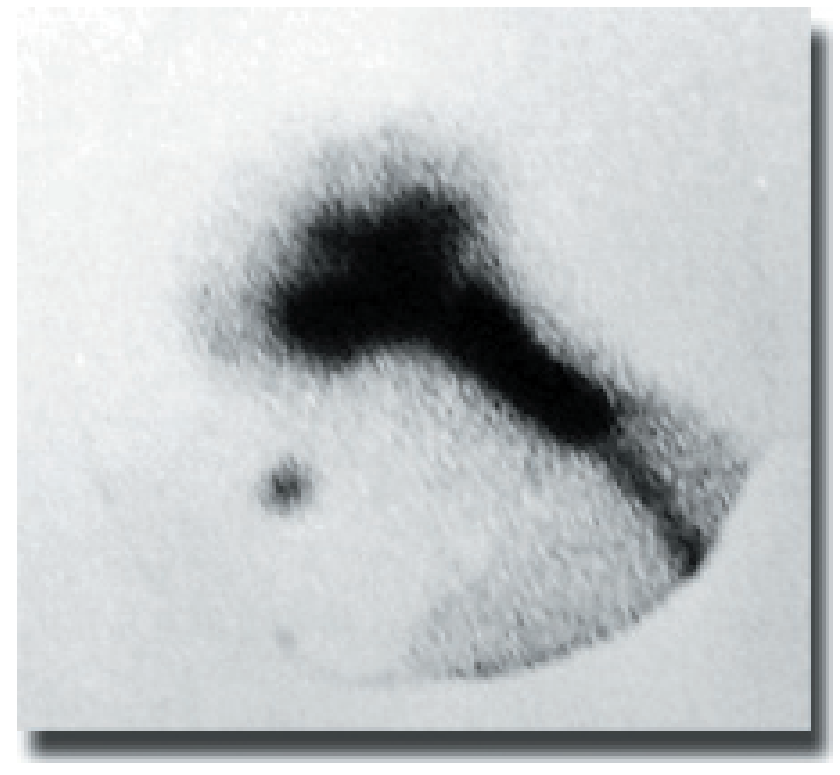

Figura. 11: Cisternografía isotópica. El lcr marcado, escapa de la silla vacía y se acumula en el seno esfenoidal.

\section{Beta-.2 transferrina}

La transferrina es un polipéptido implicado en el transporte del hierro. La Beta-1 transferrina se encuentra en el suero, secreciones nasales, lágrimas y saliva. La Beta-2 transferrina es exclusiva del lcr, perilinfa y humor acuoso. En el lcr, la Beta-2 equivale al 15\% del contenido total de transferrina, y se separa de la Beta-1 mediante electroforesis.

La prueba tiene una sensibilidad del $84 \%$ y una especificidad del $100 \%$, por lo que es un marcador válido para confirmar las fístulas de $\operatorname{lcr}^{19} \mathrm{y}$, por lo tanto, se utiliza con mucha frecuencia hoy día.

\section{Beta-trace}

Es una enzima (Lipocalin-type prostaglandin D synthase) que se produce, fundamentalmente, en las leptomeninges y se secreta hacia el lcr. En el suero se encuentra en cantidades despreciables, al igual que en las secreciones patológicas nasales. A partir de $0,68 \mathrm{mg} / \mathrm{L}$, tiene una sensibilidad del $100 \%$ y una especificidad del 91\%. Si se combina con un índice secreción nasal/suero de beta-trace superior a 4,9 , la especificidad sube al $100 \%{ }^{79}$.

\section{Localización anatómica de la fístula}

En la mayoría de las fístulas espontáneas de los pacientes con STVP, el lcr se escapa de la cavidad craneal a través de la propia silla ${ }^{97}$. Sin embargo, no es raro encontrar enfermos en los que la fístula se encuentra alejada de ella $^{81,97}$, a nivel de la lámina cribiforme ${ }^{97}$, o en las paredes laterales del seno esfenoidal ${ }^{84}$, en el caso de rinorreas. También a través del "tegmen mastoideum" en el caso de otorreas $^{78}$. En una fístula a nivel de la pirámide petrosa, el líquido puede aparecer en fosas nasales, pasando a través de la trompa de Eustaquio.

La localización anatómica de la fístula es, pues, esencial a la hora de planear el abordaje quirúrgico y, por tanto, para el éxito de su tratamiento. El mejor criterio para su localización es la detección del defecto óseo de la base de cráneo y la visualización del paso del lcr a través del mismo o la presencia de una hernia cerebral a través del defecto. Criterios secundarios son la localización del defecto óseo y la presencia de lcr en el seno paranasal colindante.

\section{Cisternografia isotópica (CI)}

Ya comentada más arriba, al tratar de los marcadores, tiene sus mismos inconvenientes, aunque fue muy empleada en el pasado. Posee una alta sensibilidad para confirmar la fístula, pero no suele localizar con precisión el sitio, debido a su limitada resolución espacial. En fístulas activas, puede orientar sobre su localización en la silla o en fosa anterior (Fig. 11)

\section{TC-Cisternografia (TCC)}

Se introduce el material de contraste mediante punción lumbar o a nivel de $\mathrm{C} 1$, donde se diluye menos $\mathrm{y}$, por tanto, es necesaria menos cantidad y se obtiene mejor opacificación del lcr. Se mantiene al paciente con la cabeza abajo, para facilitar el paso del contraste hacia los espacios subaracnoideos de la base de cráneo y se obtienen cortes coronales continuos de 1-3 $\mathrm{mm}$ de grueso. La prueba tiene una efectividad del 30-65\%, que se incrementa hasta el 85 $100 \%$ si se realiza durante el periodo de fístula activa $a^{3,68}$. Tiene los inconvenientes de un método invasivo y que provoca efectos secundarios tales como cefalea (38\%), náuseas y vómitos (38\%), que suelen remitir en menos de $24 \mathrm{~h}^{68}$. Los artefactos metálicos a partir de ortodoncias o prótesis, degradan la calidad del estudio.

\section{RM-cisternografia (RMC)}

Son imágenes en $\mathrm{T} 2$, tomadas en posición supina y en los tres planos (axial, coronal y sagital), con unos grosores de corte de 3-4 mm y distancias entre los cortes de 0,3-0,4 $\mathrm{mm}$., lo que permite una visión continua de imágenes, sin zonas de exclusión.

La secuencia de recuperación inversa en imágenes ponderadas en T2, con un tiempo inverso para la supresión de líquidos -FLAIR (Fluid Attenuated Inversion Recovery)son muy útiles para analizar mejor la naturaleza del fluido submucoso, por ejemplo, para la distinción entre la mucosa (hiperintensa) y el lcr submucoso (hipointenso).

La RMC es superior al TCC en casos de defectos múltiples durales o de fístulas inactivas o intermitentes, especialmente si el defecto dural es menor de $2 \mathrm{~mm}$. La sensibilidad de la prueba para localizar el sitio de la fístula 
alcanza el $75-85 \%$, llegando al 100\% en algunos estudios ${ }^{3}$. La RMC muestra el paso continuo de lcr desde los espacios aracnoideos a la cavidad del seno colindante, -incluso en los pacientes con fístulas inactivas-, mientras que la TCC sólo lo hace en el 50\% aproximadamente. La RMC tiene la ventaja adicional de que no expone al paciente a radiaciones, ni a sustancias extrañas. El inconveniente es que la posición supina habitual, puede no ser la ideal para detectar el escape del lcr, con la consecuencia de dar un resultado negativo en ocasiones.

Para aumentar la sensibilidad de la RMC, se ha propuesto inyectar gadolinio intratecal y poner al paciente en la posición en la que se le acentúa la rinorrea, aunque esto puede ser muy incómodo para el enfermo y no tolerarlo. Pese a que los efectos secundarios del gadolinio son menores que los del contraste yodado, con su utilización la prueba se convierte en un método invasivo, como la TCC o la CI.

\section{$T C$ de alta resolución (TCAR)}

Las TC de alta resolución permiten cortes de $1 \mathrm{~mm}$ a través de todo el área de interés, en muy poco espacio de tiempo.

Se realizan cortes coronales y axiales, con ventana ósea, a través de la fosa anterior y media. Se pueden hacer cortes de $3 \mathrm{~mm}$ y luego centrar el punto de interés con secciones de $1 \mathrm{~mm}$. La aproximación de los cortes posibilita la detección de defectos pequeños y una mejor reconstrucción en el plano sagital. Las proyecciones coronales se realizan con el paciente en decúbito prono, con la barbilla extendida, con lo que las posibilidades de visualizar la fístula son mayores, ya que esta posición provoca habitualmente la salida del líquido. Estas proyecciones no son las adecuadas para detectar fístulas a nivel de la pared posterior del seno frontal, donde sería necesario un estudio con cortes sagitales. El inconveniente es la alta radiación para los ojos, que son muy sensibles a ella. En su defecto, se puede paliar con la reconstrucción de los cortes coronales. Esta técnica proporciona evidencia indirecta de la fístula y muestra su localización en el $84,5 \%$ de los $\operatorname{casos}^{83}$. Las imágenes deben de verse tanto en ventana de tejidos blandos, como en la ventana ósea.

El estudio se considera positivo en presencia de un defecto óseo, con aire o densidad de líquido en comunicación, o bien herniación de tejido cerebral o meninges. Las limitaciones vienen dadas por la imposibilidad de diferenciar entre ler y sangre, moco o pus, en los senos paranasales. También por los artefactos que provocan las prótesis y ortodoncias.

\section{Esquema para el manejo diagnóstico en la fístula espon- tánea de los pacientes con STVP}

Una vez confirmada la presencia de una fístula desde el punto de vista clínico y analítico, mediante un marca- dor de lcr, algunos autores ${ }^{3}$ recomiendan, a menos que el enfermo tenga alguna contraindicación para exponerse a un campo magnético, comenzar con un estudio de RMC. Si es negativo o no es adecuado para una planificación quirúrgica, se realiza una TCAR. Si también es negativo y la sospecha persiste, o en los casos complicados, como la recurrencia postoperatoria de la fístula, se realiza una TCC. La razón por la que dejan la TCC como última opción es por su carácter invasivo, con las consiguientes molestias para el paciente y por los efectos secundarios de los contrastes.

\section{Etiología y patogenia de la STVP}

\section{Diafragma de la silla turca incompetente}

Desde los estudios de autopsia de Schaeffer en $1924^{80}$, se sabe que el orificio del diafragma de la silla turca tiene, en algunos casos, variaciones en su diámetro, de manera que puede incluso ser tan amplio como para que el diafragma quede reducido a un pequeño ribete que circunvala la apertura craneal de la silla turca.

Busch en $1951^{16}$ tras un estudio de 788 necropsias, clasificó el diafragma en tres tipos: normal, ampliado y casi ausente, correspondiendo a esta última variante un $20 \%$ de los casos. Algunos de ellos tenían la hipófisis aplanada y rechazada contra la porción infero-posterior de la fosa pituitaria y este autor fue el primero que acuñó el término de silla turca vacía (5\% del total de las necropsias), resaltando que la mayoría correspondían a mujeres $(5,66: 1)$.

\section{Pulso sistólico, maniobras de Valsalva e hipertensión in- tracraneal}

La ausencia del diafragma de la silla expone a la glándula hipofisaria a la fisiopatología de la presión intracraneal.

Desde que Du Boulay ${ }^{26,27}$, en 1966, y luego Kaufman ${ }^{55}$ en 1968, propusieran la participación de las pulsaciones del lcr y la influencia de hipertensión intracraneal, hoy día existe consenso en que ambos factores son importantes en el desarrollo de la silla vacía, cuando el diafragma es incompetente.

Es un hecho que la incidencia de la STVP aumenta con la edad desde un $11,1 \%$, en la segunda década, a un $48,8 \%$ en la octava $\mathrm{a}^{34}$, lo que es congruente con un mayor tiempo de exposición de la glándula a las pulsaciones del lcr y al efecto de la presión intracraneal sobre ella, incluido los aumentos transitorios que se producen con los esfuerzos o las maniobras de Valsalva.

Desde el trabajo de Kaufman, han ido apareciendo estudios en los que se demuestra la asociación de la hipertensión intracraneal crónica idiopática (HICI) y la STVP, con una incidencia que va del 10 al $94 \%$ de los $\operatorname{casos}^{13,41,86,101,103}$. 


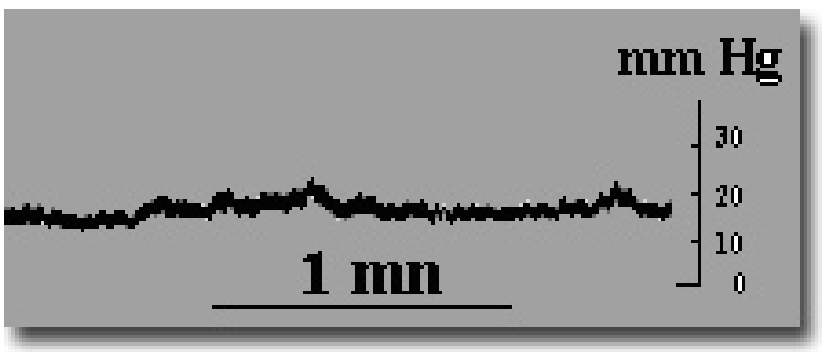

Figura 12. Registro de PIC diurno, por vía lumbar, de un paciente con STVPS, con presiones medias de $18 \mathrm{~mm}$. $\mathrm{Hg}$.

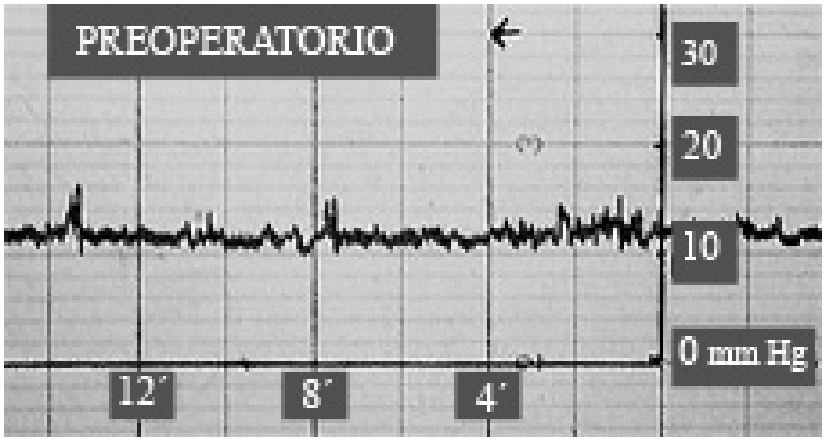

Figura 14. Registro preoperatorio de PIC, por vía lumbar, de un paciente con STVPS y rinorrea.

Yuh y col. ${ }^{108}$, estudiaron las dimensiones de la hipófisis y el grado de silla turca vacía en 40 enfermos con hipertensión intracraneal crónica idiopática, comparándola con otro grupo de 37 casos de hipertensión intracraneal aguda (HIA) y 23 sujetos normales. Concluyen que no existían diferencias entre el grupo de HIA y el de las personas normales. Sin embargo, en la HICI existían diferentes grados de silla turca vacía en el $85 \%$ de los casos, con una sensibilidad del $80 \%$ y una especificidad del $92 \%$, lo que demuestra que el carácter crónico de la $\mathrm{HI}$, tiene una especial relevancia en el desarrollo de la STVP.

Entre los pacientes de STVP, la predominancia de mujeres con cefalea, obesidad e hipertensión arterial, hace recordar la semiología del pseudotumor cerebral. Sin embargo, el signo principal para su diagnóstico, que es el edema de papila óptica, está generalmente ausente. De hecho, el cuadro clásico de pseudotumor cerebral sólo se encuentra en el 9,8\% de los casos de STVP ${ }^{25}$. Pese a que se han publicado casos de HICI que han cursado sin papiloedema en los adultos ${ }^{62,69,106}$ y en un $29 \% \%^{63}$ en niños, la asociación de la STVP con una hipertensión intracraneal crónica y subclínica es objeto de controversia.

En 1983, nosotros estudiamos una serie de 21 pacientes con STVP (VII Reunión científica de neurocirugía de Levante. Alicante), ninguno de los cuales, excepto dos, presentaba éxtasis de papila óptica en el examen del fondo ocular. El protocolo incluía la valoración de la PIC basal y mediante registro nocturno a través de una punción lumbar.

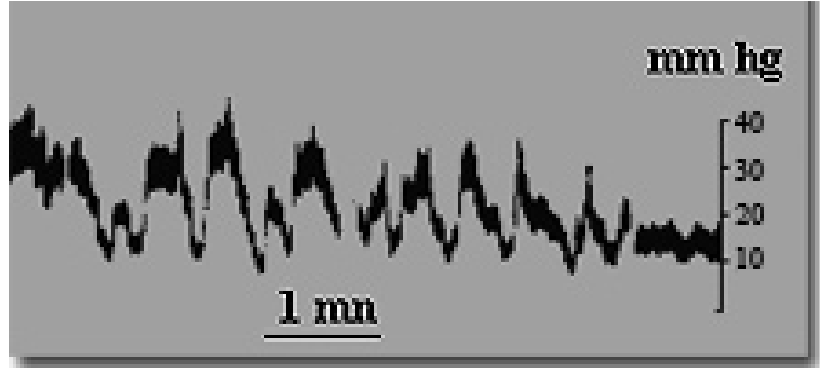

Figura 13. Registro de PIC nocturno de la misma paciente de la figura anterior. Abundantes ondas B, con picos de hasta $40 \mathrm{~mm}$. $\mathrm{Hg}$.

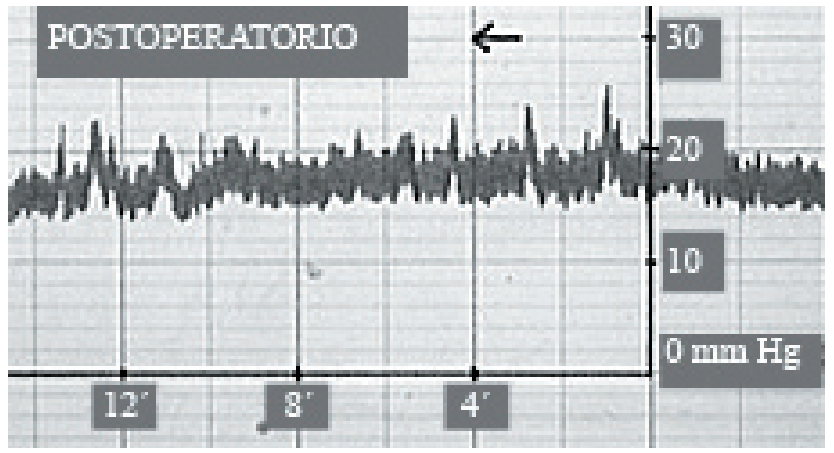

Figura 15. Registro postoperatorio de PIC de la misma paciente de la figura anterior.

El resultado fue que el 33\% de los casos, en su mayoría mujeres obesas, tenían un presión intracraneal en el rango de los 14-18 mm Hg., con elevaciones nocturnas que subían en algunos casos por encima de los $30 \mathrm{~mm} \mathrm{Hg}$. y abundantes ondas B que estaban ausentes en los registros diurnos (Fig. 12 y 13). Esta hipertensión intracraneal moderada, crónica y subyacente en la STVP, ha sido puesta en evidencia también por otros autores ${ }^{11,24,33,65,82}$. Maira $\mathrm{G}$ y col.$^{65}$ han publicado una serie de 142 pacientes con STVP, en los que realizan un estudio sistemático de PIC basal y un test de infusión, para valorar la reserva de absorción del lcr. Solo el $25 \%$ de los casos presentaban papiledema en la exploración clínica. Sin embargo, un $76,8 \%$ de los enfermos, tenían presiones intracraneales en el rango de 14-26 mm Hg., y en el 80,73\% estaba deteriorado el test dinámico de lcr. Más aún, un 19,2\% de los pacientes con registros de PIC basales normales, tenían alterada la dinámica del lcr en el test de infusión lumbar.

El diagnóstico de la hipertensión intracraneal subyacente en una proporción no despreciable de casos con STVP sintomática es importante, porque condiciona el manejo del paciente. La HI puede hacerse evidente sólo después de sellar la fístula espontánea de $1 \mathrm{cr}^{70}$, como sucedió con una de nuestras pacientes (Fig. 14 y 15), siendo preciso la colocación de una derivación lumbo-peritoneal de lcr.

\section{Patogenia de las alteraciones endocrinológicas}

Los mecanismos por los que existen alteraciones del 
funcionamiento hormonal hipofisario en algunos pacientes con STVP, son especulativos. La acodadura del tallo hipofisario sobre el dorso de la silla turca ha sido implicada en las disfunciones hormonales adenohipofisarias, suponiendo que dificulta la llegada, por los vasos porta, de las hormonas de relación hipotalámicas hasta la adenohipófisis, incluido el PIF que inhibe la secreción de prolactina ${ }^{40}$. De hecho se ha publicado que el ritmo y dinámica de la PRL se normalizan tras corregir la $\mathrm{HI}$ en los pacientes con STVP ${ }^{66} \mathrm{y}$, en una de nuestras pacientes, también cedió la hiperprolactinemia. Sin embargo, la diabetes insípida es extraordinariamente rara en la STVP, en comparación con las disfunciones de las hormonas adenohipofisarias, lo que induce a pensar que existe una distinta susceptibilidad en la hipófisis anterior con respecto a la posterior, ante los embates de presión de la onda sistólica del lcr y la presión intracraneal. Esta diferente vulnerabilidad puede venir condicionada por la diferencia en la irrigación sanguínea de esas dos partes de la glándula, ya que mientras la neurohipófisis recibe un excelente aporte arterial, la adenohipófis está irrigada casi de manera exclusiva por los vasos porta, de naturaleza venosa ${ }^{71,74,107}$, con presiones sanguíneas intraluminares muy bajas, en el rango de 2,9 $\mathrm{mm}$ de $\mathrm{Hg} .{ }^{32} \mathrm{El}$ hecho de que las alteraciones hormonales apenas se normalizan, tras corregir la hipertensión intracraneal ${ }^{66}$, puede ser debido a una atrofia isquémica de la adenohipófis, como punto final de la involución progresiva de la glándula que limita su recuperación funcional. Sin embargo, la atrofia puede representar un fenómeno tardío, ya que se han publicado casos en los que la hipófisis ha recuperado su volumen normal ${ }^{60,109}$ tras la corrección de la $\mathrm{HI}$ mediante tratamiento con acetazolamida o mediante una derivación de $1 \mathrm{lcr}^{60,109}$.

\section{Otros factores que se han implicado en la patogenia de la STVP \\ Obesidad}

En la obesidad troncular de los pacientes que padecen pseudotumor cerebral se ha demostrado un aumento de la presión intra-abdominal, lo que incrementa la presión venosa central y dificulta el drenaje venoso cerebral ${ }^{92}$. La presión venosa intracraneal se eleva, contribuyendo a aumentar la presión intracraneal ${ }^{53,92}$. Es un mecanismo a tener en consideración para el manejo de las pacientes obesas $\left(>25 \mathrm{Kg} / \mathrm{m}^{2}\right)$ con STVP e HIC ${ }^{94}$. De hecho, el tratamiento con azetazolamida no mejora el cuadro de HIC si no se acompaña de una dieta que consiga una pérdida de peso de al menos el $6 \%{ }^{51}$. Sugerman y $\mathrm{col}^{93}$, sometieron a cirugía gástrica reductora a 24 mujeres con obesidad mórbida e HICI, consiguiendo la curación de la hipertensión intracraneal a los cuatro meses de la intervención en el 95,8\% de ellas, así como de la única rinorrea de la serie.

\section{Hipertensión arterial}

Se ha propuesto que la hipertensión arterial es un factor que puede concurrir para agravar los efectos de la pulsación del lcr y de la hipertensión intracraneal sobre la hipófisis, en ausencia del diafragma sellar. Sin embargo, De Marinis y col. ${ }^{25}$ no encuentran diferencia en la prevalencia cuando se compara el grupo de pacientes con STVP con la población general.

\section{Patogenia de la silla turca vacía sin hipertensión intracraneal}

Existe una proporción importante de enfermos con STVP en los que no es posible demostrar la existencia de una hipertensión intracraneal en los registros de PIC. Para estos casos se han sugerido diversas explicaciones en la literatura médica. Algunas de ellas se exponen a continuación. Son hipótesis elaboradas en base de indicios indirectos para explicar algunos casos de STVP, pero que precisan de confirmación.

\section{Involución fisiológica de la hipófisis}

Foresti y $\mathrm{col}^{34}$, en un estudio con RM de 500 pacientes, encontraron que la prevalencia de la STVP aumenta con el paso de los años, por lo que proponen que la involución fisiológica de la glándula, relacionada con la edad, es un factor que interviene en el desarrollo de la STVP cuando el diafragma es incompetente.

\section{Embarazos múltiples}

Ya que la hipófisis aumenta más de dos veces su volumen durante el embarazo ${ }^{42}$, y en razón a los antecedentes de embarazos múltiples en una proporción de mujeres con STVP, se ha postulado que, tras agrandar la silla turca y, finalmente, involucionar de nuevo a su tamaño normal tras el parto, la glándula deja parte del espacio intraselar libre para que se introduzca lcr, en presencia de un diafragma sellar incompetente. Sin embargo, en un estudio realizado en 50 mujeres multíparas no se encontró ningún aumento significativo de la silla turca ${ }^{75}$.

\section{STVP congénita}

Zucchini y col. ${ }^{111}$ estudiaron 43 niños con STVP y alteraciones hipotálamo-hipofisarias, sobre todo déficit aislado de HG (46,5\%) y déficit múltiple de hormonas (39,5\%): no encontraron un aumento de la silla turca en ninguno de ellos. En particular, en los que padecían déficit hormonal múltiple, la silla turca era más pequeña, con un alto porcentaje de anomalías del tallo y neurohipófisis, por lo que proponen que la STV de estos pacientes sea una anomalía congénita y no adquirida. Sin embargo, el $64,7 \%$ de estos niños habían tenido antecedentes de un proceso perinatal que podría haber cursado con hipoxia (parto de nalgas, asfixia, prematuridad y convulsiones neonatales), por lo 
que la involución de la glándula podría ser consecuencia de ella.

\section{Apoplejía y otros procesos destructivos de la hipófisis}

Se ha sugerido que otros procesos no tumorales pueden dar lugar a la destrucción parcial o total de la adenohipófisis (apoplejía posparto, infarto en diabéticos, infecciones); el episodio clínico de la destrucción pudiera pasar desapercibido en alguno de estos casos con el resultado de una STV, aunque posteriormente se detecte su insuficiencia hormonal.

El infarto por hipotensión arterial grave durante el parto -Síndrome de Sheehan- suele ser un episodio silente, en el que la única manifestación clínica inmediata puede ser la insuficiencia de la secreción mamaria, haciendo imposible la lactación del niño, y la persistencia de la amenorrea. El fracaso hipofisario puede no hacerse evidente hasta mucho tiempo después del parto, incluso años. La mayoría de estas mujeres muestran una silla turca vacía de tamaño normal ${ }^{56}$.

En este grupo, también se encuentra la destrucción glandular por autoanticuerpos de la hipofisitis linfocitaria ${ }^{91}$. Esta teoría está apoyada por la existencia, en los pacientes de STVP, de una prevalencia más alta de anticuerpos a la proteína $\mathrm{M}$ citosólica hipofisaria $(28 \%)$ con respecto a la población normal (6-8\%). En ellos, la silla turca tampoco se encuentra aumentada de tamaño.

\section{Patogenia de las alteraciones visuales en la STVP}

El mecanismo mediante el cual se producen las alteraciones visuales en la STVP no está aclarado y es objeto de debate. Tradicionalmente, se ha atribuido a un descenso de las vías ópticas hacia el interior de la silla turca ${ }^{72}$, lo que es francamente excepcional en el grupo de STVP, en contraposición con la STVS.

Se ha aducido que las alteraciones visuales en estas hernias intraselares son consecuencia de la tensión y acodadura de las vías ópticas, por estar fijadas, por delante, a los agujeros ópticos $\mathrm{y}$, por detrás, a los tubérculos geniculados; además, pueden contribuir las distorsiones vasculares que llevarían a la isquemia de los nervios ópticos o del quiasma ${ }^{23,44}$. En los pocos pacientes operados por este motivo, con resultados variables, se ha encontrado un quiasma descolgado hacia el interior de la silla ${ }^{5,105}$, nervios ópticos adelgazados, o bien aracnoiditis ${ }^{23}$ a la que se ha atribuido el deterioro de la vascularización óptica. Pero también se han operado casos en los que se ha constatado una situación normal de las vías ópticas, obteniéndose, sin embargo, una mejoría del cuadro visual tras la operación ${ }^{44,57}$.

Muchas de estas publicaciones se han producido cuando aún no era conocida la implicación de una hipertensión intracraneal benigna y subclínica, en algunos pacientes
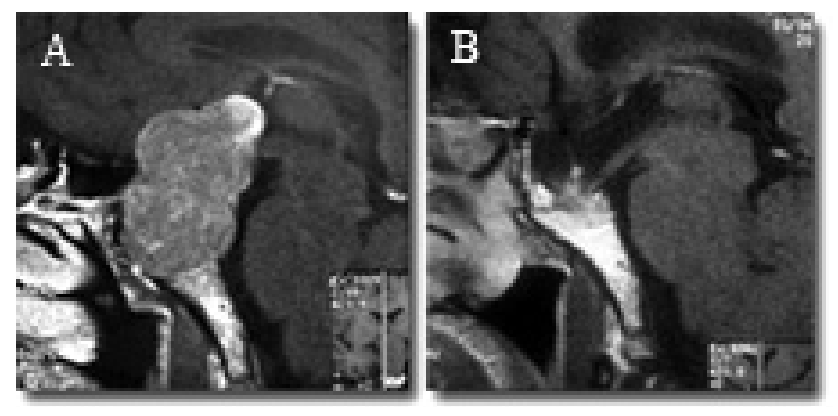

Figura 16. A: RM sagital de un macroadenoma de hipófisis. B: silla turca vacía, tras el tratamiento quirúrgico del tumor. Tanto el quiasma óptico, como la porción anterior del tercer ventrículo, están herniados dentro de la fosa sellar sin que el paciente manifestara alteraciones visuales.

afectos de este síndrome. De manera que es posible que sea esa hipertensión intracraneal la responsable de las alteraciones visuales y no la propia silla turca. Si es así, no es de extrañar que los enfermos mejoren después de la descompresión de lcr que se produce durante la intervención quirúrgica.

En nuestra experiencia, un 56\% de los pacientes operados por padecer un macroadenoma hipofisario, con invasión supraselar, o que han padecido una apoplejía, presentan una silla turca grande, vacía y, en mayor o menor grado, un descenso de las vías ópticas y porción anterior del III ventrículo, hacia su interior (Fig. 16). Sin embargo, esta alteración anatómica rara vez se ha acompañado de un deterioro visual.

Por otro lado, la técnica quirúrgica que se ha empleado en la mayoría de los casos ha sido el abordaje transesfenoidal y el relleno de la fosa sellar con músculo o grasa, para levantar el quiasma hasta su posición anatómica normal. Pero, desde la disponibilidad de la RNM, sabemos que estos autoinjertos terminan por necrosarse y reabsorberse en su mayor parte, volviéndose a reproducir, en pocos meses, las condiciones anatómicas para la recidiva del cuadro de alteración visual, cosa que, en nuestro conocimiento, no se ha publicado todavía. Para evitar el problema de la reabsorción del autoinjerto, Nagao y col. ${ }^{73}$ propusieron la obliteración extradural de la silla turca, mediante un balón que se rellena de silicona, pero Gazioglu y col. ${ }^{39}$ pusieron en evidencia, con la publicación de sus tres casos, que estos balones se desinflan con el tiempo, volviéndose a reproducir la silla turca vacía en la RM. Pese a ello, ninguno de los pacientes sufrió un empeoramiento de las alteraciones visuales.

Hay que recordar, de manera adicional a lo expuesto, que la población general también es subsidiaria de padecer alteraciones visuales que, con frecuencia, son autolimitadas. La diabetes mellitus, junto con la hipertensión arterial, 


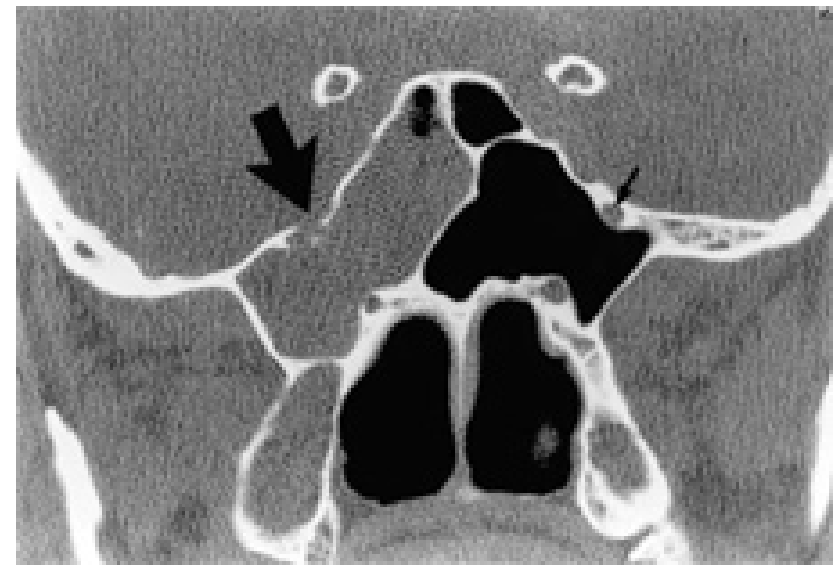

Figura 17. Corte coronal a nivel del seno esfenoidal con TAC de alta resolución. Defecto en la pared lateral del seno esfenoidal en el lado derecho, a través del foramen rotundum (flecha larga). La flecha corta señala hacia el foramen normal, en el lado izquierdo (Cortesía@AJNR8).

dos entidades de alta prevalencia, pueden causar déficit visuales por isquemia. Beattie y Trope ${ }^{7}$ encontraron, en 7 de 8 pacientes con silla turca vacía, alteraciones típicas de glaucoma en el disco óptico y campos visuales; cuatro de ellos con glaucoma de ángulo abierto primario, y tres con glaucoma de baja tensión.

Por tanto, a no ser que aparezcan otras evidencias, hay que mirar con recelo la implicación de la STVP en las alteraciones visuales que puedan presentar estos enfermos.

\section{Fístula de líquido cefalorraquídeo}

La mala "compliance" intraselar para amortiguar la onda sistólica del lcr en los casos de diafragma incompetente $^{26,27} \mathrm{y} / \mathrm{o}$ una hipertensión intracraneal crónica oculta $^{65,70,81}$ o manifiesta ${ }^{55,97}$, puede finalmente erosionar el débil suelo de la silla turca u otro punto débil de la base de cráneo $^{78,81,84,97}$ y provocar una rinorrea.

Shetty y $\operatorname{col}^{84}$, publicaron 11 pacientes con fístulas a nivel de las paredes antero-laterales del seno esfenoidal, la mayoría en la zona de unión con el suelo de la fosa media, comparándolos con un grupo control de 100 personas normales. En el grupo de las fístulas existía una alta proporción de enfermos con excesiva neumatización lateral del seno esfenoidal (91\%) (Fig. 17) y vellosidades aracnoideas (Fig. 18), que horadaban pequeñas cavidades en la porción antero-medial del suelo de la fosa media (63\%), que no se encontraban en ningún caso del grupo normal de control; por esto, los consideraron como factores predisponentes para el desarrollo de la fístula, ya que son puntos débiles que pueden ceder ante el empuje de la presión intracraneal. El hecho de que el 63\% presentaba una STVP y que en el 91\%, la morfología de la pared lateral del seno esfenoidal fuera cóncava en sentido craneal, les induce a pensar que

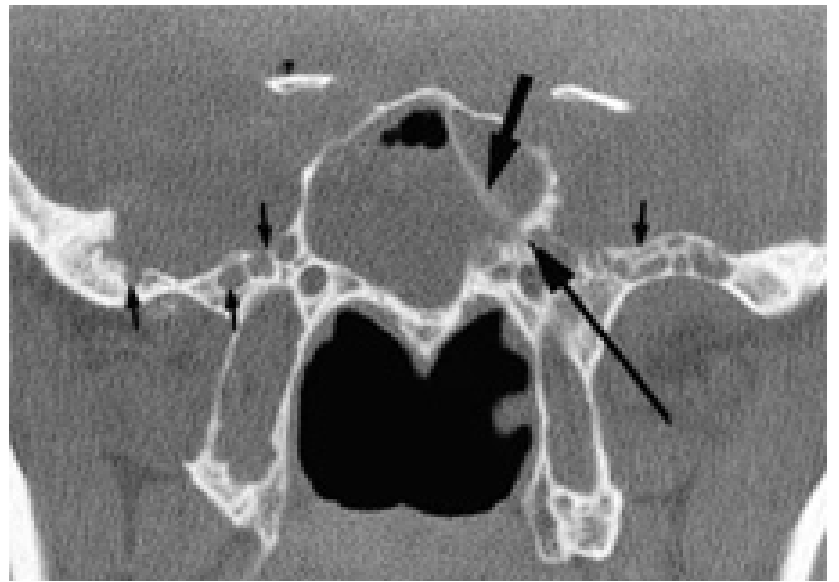

Figura 18. Corte coronal a nivel del seno esfenoidal con TAC de alta resolución. La flecha larga en el lado izquierdo, apunta al defecto en la porción anterior de la pared lateral del seno esfenoidal, justo por debajo de la inserción del tabique intraesfenoidal. Las flechas pequeñas, señalan los nichos aracnoideos en el suelo de la fosa media. (Cortesía@AJNR84).

ambas patologías pueden compartir la misma alteración de la presión intracraneal que sufren algunos pacientes de STVPS.

\section{Consideraciones finales a la patogenia de la STVP}

Es importante entender que la STV es un concepto radiológico, reflejo de un detalle anatómico, que no representa en si mismo una enfermedad. Por el contrario, es un hecho que comparten varias enfermedades que, por una razón u otra, la provocan o la acentúan, llegando a producir en ocasiones, una alteración en el funcionamiento de la hipófisis.

La labor del médico es averiguar cual es la enfermedad subyacente a la STV, si es que existe alguna que, en el momento de atender al paciente, esté en actividad. La terapéutica va dirigida a la entidad nosológica generadora de los síntomas, incluidas las alteraciones funcionales que pueda estar provocando en la glándula, o que haya dejado como secuela.

\section{Tratamiento quirúrgico en la STVP}

No es raro que se remita a la consulta de neurocirugía pacientes para ser valorados por una silla turca vacía, que se ha descubierto tras hacerle una TC o RM por cualquier motivo.

Si la anamnesia y exploración, incluido el fondo ocular, no descubre ningún síntoma, alteración neurológica, o endocrinológica, que pudiera estar relacionado con la clínica habitual del síndrome, no es necesario realizar pruebas adicionales, ya que estos pacientes no precisan 
tratamiento.

\section{Indicaciones del tratamiento quirúrgico}

El tratamiento quirúrgico se realiza en los pacientes con STVP sintomática, cuando se presentan alguna de las siguientes circunstancias:

1. Fístula de lcr.

2. Hipertensión intracraneal crónica idiopática subyacente a una fístula de lcr o con cefalea y alteración visual grave que no responden al tratamiento médico.

3. Deterioro visual por hernia de las vías ópticas hacia el interior de la silla turca.

4. Cefalea grave que no responde al tratamiento médico.

5. Patología intracraneal que condiciona una hipertensión intracraneal crónica, bien tumoral, malformativa o por hidrocefalia.

Esta revisión se va ha centrar en las cuatro primeras que, como se ha expuesto previamente, pueden presentarse de manera aislada cada una de ellas, o concurrir en un mismo paciente, lo que condiciona su manejo.

\section{Fístula de líquido cefalorraquídeo}

La rinorrea en la STVP, ha sido tratada mediante abordajes intradurales transcraneales o transesfenoidales a la silla turca, y mediante implantación sistemas de derivación de lcr, con un alto índice global (41-46\%) de fracaso en el primer intento ${ }^{35,37,65}$, sea cual sea el tipo de intervención realizado.

\section{Derivación de líquido cefalorraquídeo}

Un planteamiento terapéutico racional es la colocación de una derivación de lcr en aquellos pacientes en los que se ha detectado una hipertensión intracraneal crónica idiopática o una alteración de la dinámica del $\operatorname{lcr}^{65}$, o bien en los que no se ha podido identificar el sitio de la fístula.

En las derivaciones lumbo-peritoneales, la sencillez del procedimiento está ensombrecida por el alto índice de mal funcionamiento, que lleva a revisiones múltiples del sistema ${ }^{15,65}$, así como ocasionales complicaciones como el excesivo drenaje, provocando cuadros de hipotensión intracraneal, o dolor radicular, que suele ser autolimitado. Mas raramente se ha publicado algún caso con hidrocefalia, en que la diversión del lcr ha provocado neumoencéfalo ${ }^{50}$. En las personas obesas, se ha señalado como una posible causa del mal funcionamiento de la derivación, al aumento típico de presión intra-abdominal que tienen estos enfer$\operatorname{mos}^{93}$.

Tres de los siete pacientes a los que se les practicó, de manera no selectiva, una derivación de lcr en la serie publicada por García-Uría y col $^{37}$, tuvieron recidiva de la rinorrea a largo plazo ( 0,8 años de promedio), lo que con- sideran como resultado muy pobre en comparación con los obtenidos cuando hacen un abordaje quirúrgico directo de la fístula.

\section{Reparación quirúrgica de la fístula}

Para aquellos pacientes en los que no existe alteración demostrable de la PIC o de la dinámica del lcr y el sitio de la fístula está identificado, la reparación quirúrgica de la fístula es la mejor opción. Pese a este esquema de tratamiento, un $38 \%$ de los pacientes necesitarán los dos procedimientos ${ }^{65}$.

\section{Abordaje transesfenoidal con microscopio óptico}

La vía endonasal con microscópico óptico, se popularizó a finales del último siglo, en especial para los casos de fístulas a través de la silla turca, utilizándose distintas técnicas para el relleno de la fosa sellar mediante injertos libres (grasa, músculo, fascia y tabique nasal), bien por dentro ${ }^{47}$ o por fuera de la duramadre ${ }^{45}$, o ambas ${ }^{102}$, no siendo infrecuente la oclusión del seno esfenoidal con grasa autóloga.

García-Uria y col ${ }^{37}$ operaron 14 pacientes con este abordaje, obteniendo una curación inmediata en el 85\% de ellos, con $33 \%$ de recidivas en un promedio de 4,2 años.

\section{Reparación por endoscopia nasal}

En los últimos años, se han ido publicando los resultados de la reparación endoscópica endonasal, en particular para fístulas de las masas laterales del etmoides, lámina cribosa, surco olfatorio y seno esfenoidal lográndose una efectividad, al primer intento, de alrededor del 90\% 49 . Sin embargo, un $15 \%$ de las fístulas recidivan en un plazo de 2 años, con un promedio de 7 meses $^{112}$, con independencia de la técnica endoscópica empleada. El único factor, que sí está relacionado con la recidiva de la rinorrea, es la presencia de hipertensión intracraneal, en especial de hidrocefa$\operatorname{lia}^{49,99}$, que puede hacerse evidente solo después de reparar la fístula ${ }^{70}$.

En las fístulas muy laterales de senos esfenoidales amplios, Locatelli y col $^{64}$ realizan un acceso ampliado a través del etmoides y base de la apófisis pterigoide. Pero en general, para estos casos, se prefiere un abordaje intracraneal subtemporal, como se comentará después.

Aunque se han utilizado, en la reparación endoscópica, injertos pediculados vascularizados ${ }^{46,64,99}$, utilizando mucoperiostio de la concha media o mucopericondrio de tabique nasal, lo habitual es utilizar injertos libres de mucosa, periostio, cartílago y hueso en distintas combinaciones, obtenidos de la propia fosa nasal, no existiendo diferencias estadísticas en cuanto a los resultados obtenidos con las diferentes técnicas y materiales ${ }^{49}$.

Una vez localizado el lugar de la fístula, se extirpa la mucosa de alrededor del defecto óseo ${ }^{64,99}$. Si este es grande y no existe peligro de lesionar estructuras nerviosas 
o vasculares, se separa la dura madre intracraneal de los bordes del defecto, creando un pequeño espacio para colocar el injerto (underlay). Si existe un pequeño meningocele, basta coagularlo con pinzas bipolares, para que se retraiga. Si es más grande o se trata de un meningoencefalocele, hay que extirparlo por la base ${ }^{64}$. El defecto óseo se repara con hueso o cartílago nasal y se apone otro injerto extracraneal, que se fija con una lámina de celulosa oxidada (surgicel) o gelatina (espongostan). El espongostan es un buen material para separar el injerto de la gasa con la que se tapona la fosa nasal, ya que al retirar esta 24-48 horas después, se evita que se venga con ella el injerto.

Si el defecto es pequeño o la duramadre está firmemente adherida al hueso, como pasa a nivel de la lámina cribosa o la "fovea etmoidalis", basta con adosar el injerto sobre el mismo (overlay).

En el seno esfenoidal, la fístula se puede reparar mediante la técnica de injerto libre "underlay" o "overlay" 99 $\mathrm{y}$ es frecuente la técnica obliterativa adicional del mismo, utilizando grasa autóloga, obtenida del abdomen ${ }^{49,99}$. En estos casos, el mucoperiostio del seno se extirpa por completo, para evitar el desarrollo de mucoceles.

La tinción del lcr con el amarillo verdoso con fluoresceína es muy útil para facilitar la localización de la fístula en los abordajes endoscópicos. Sus reacciones adversas son raras y relacionadas con un mal uso del producto, bien por emplear concentraciones o cantidades inadecuadas o por su aplicación por vía suboccipital ${ }^{104}$. Generalmente consisten en debilidad de miembros inferiores y epilepsia.

Se administra por vía intratecal, mediante punción lumbar. Para disminuir la posibilidad de cefalea post-punción, por pérdida de lcr por el orificio que deja la aguja, se recomienda utilizar agujas del 24 , con punta roma ${ }^{6}$. Se tiene que comprobar que sale lcr de manera espontánea, ya que si se inyecta en el espacio subdural puede causar aracnoiditis. Se aspira de manera lenta $8-10 \mathrm{cc}$., se mezcla $10 \mathrm{~mm}$ de lcr con $0,5 \mathrm{ml}$ de fluoresceína al $5 \%$ para uso intratecal y se inyectan lentamente en el espacio subaracnoideo. El paciente se coloca $10^{\circ}$ en posición de Trendelemburg. El procedimiento se realiza unas cuatro horas antes de la endoscopia nasal ${ }^{6}$. El uso de la fluoresceína no sólo sirve para confirmar y localizar la fístula, sino para comprobar su reparación.

\section{Craneotomía}

En general, el clásico abordaje transcraneal queda actualmente reservado para los casos de fístulas espontáneas en STVP, en los que no se ha podido localizar el lugar por el que se produce el escape del lcr, así como en las fístulas de los recesos laterales del seno frontal, donde al acceso endoscópico es difícil ${ }^{64}$ y puede lesionar el conducto lagrimal. También en los esporádicos casos de fístulas muy laterales del seno esfenoidal, donde también el acceso endoscópico es difícil. En estos pacientes, la fístula suele estar en la porción antero-medial de la fosa media, generalmente antero-lateral al foramen rotundum ${ }^{58,84}$ y se reparan mediante un abordaje subtemporal, intra-extradural, separando la hernia meníngea y cerebral que pueda haber a nivel del defecto, procediéndose después a taponarlo con grasa y a la reparación de la duramadre.

García-Uría y $\mathrm{col}^{37}$, obtuvieron un $94 \%$ de curación inmediata en 17 pacientes mediante el abordaje intradural subfrontal en las fístulas de la silla turca. Sin embargo, el $43 \%$ presentaron recurrencia en un tiempo de evolución promedio de 7,28 años.

\section{Drenaje postoperatorio de líquido cefalorraquídeo}

El drenaje lumbar transitorio postoperatorio, tras la reparación de las rinorrea, no está generalizado ${ }^{49}$; hay autores que lo emplean y otros que no lo consideran necesario, obteniendo los mismos resultados. Sin embargo, se han publicado casos en los que, tras el sellado de la fístula, se ha desencadenado un cuadro de hipertensión intracraneal o de hidrocefalia ${ }^{49,70}$, que ponen en peligro el éxito de la operación, como sucedió en una paciente de nuestra serie. Por otro lado, y debido a que en el grupo específico de la STVP existe una no despreciable proporción de pacientes que tienen una hipertensión intracraneal subyacente o alteraciones en la dinámica del lcr, es razonable su utilización, no sólo para dar un margen para la curación del defecto reparado, sino para detectar la presencia de hipertensión intracraneal, ya que necesitaría un tratamiento médico adicional específico o una derivación permanente de lcr. A este respecto, se ha sugerido dejar un drenaje continuo lumbar durante 3-5 días, procurando evitar un drenaje excesivo. Uno o dos días después de retirar el catéter, y antes de que el paciente sea dado de alta, se vuelve a registrar la PIC mediante una punción lumbar, para confirmar que las presiones continúan normales ${ }^{49}$.

\section{Hipertensión intracraneal crónica idiopática}

Si se demuestra una hipertensión intracraneal, debe de manejarse al paciente como un pseudotumor cerebral.

En los pacientes con obesidad $>35 \mathrm{Kg} . \mathrm{m}^{2}$ y comorbilidad, entre la que se ha propuesto la $\mathrm{HICI}^{93}$ o bien con $>40 \mathrm{Kg} / \mathrm{m}^{2}$, está indicado la cirugía gástrica, ya que se ha demostrado que soluciona el problema de la hipertensión intracraneal a medio y largo plazo $^{93}$. En este grupo de pacientes con obesidad mórbida, el adelgazamiento es muy difícil de conseguir con medidas convencionales, en especial cuando están bajo tratamiento con dexametasona.

\section{Cefalea y alteraciones visuales en la Hipertensión intra-} craneal crónica idiopática

Si el tratamiento médico de la HICI y la analgesia convencional no son efectivos para controlar la cefalea, 
o existe un compromiso visual peligroso, está indicada la implantación de un sistema de derivación de $\operatorname{lcr}^{15}$. La cirugía gástrica no puede ser considerada cuando se necesitan medidas correctoras inmediatas de la hipertensión intracraneal. Si la derivación de lcr no es efectiva, la fenestración de los nervios ópticos ${ }^{43}$, vía orbitotomía lateral o el abordaje medial transconjuntival ${ }^{20}$, está sustituyendo a la clásica craniectomía temporal descompresiva propuesta por Dandy ${ }^{43}$.

\section{Hernia de las vías ópticas hacia el interior de la silla turca y cefalea}

Para la corrección del descenso de la vía óptica hacia el interior de la silla turca -quiasmapexy-, tanto primaria como secundaria, se ha utilizado el relleno de la silla turca con tejidos antólogos ${ }^{5,59,72,77,100,105}$, tales como músculo, grasa, cartílago o hueso, a través de un abordaje transesfenoidal, microquirúrgico o endoscópico. Guiot ${ }^{45}$ propuso el relleno extradural con fascia lata y pequeñas piezas de hueso de tabique nasal y grasa. Para obviar el problema de la reabsorción del injerto, se han utilizado balones epidurales rellenados con silicona ${ }^{39,73}$. Por último, dada la posibilidad de que se desinflen ${ }^{39}$, se ha propuesto utilizar coils de silicona ${ }^{110}$ o láminas adosadas del mismo material $^{57}$. La escasa casuística basada fundamentalmente en casos aislados, con resultados variables, no permiten sacar conclusiones referente a la eficacia de esta cirugía.

Se han publicado casos esporádicos s, $^{48,73}$ en los que la elevación de la dura madre del suelo de la silla turca, sin apertura de la cisterna aracnoidea, ha curado la cefalea en pacientes con STVP que, en ocasiones, es grave y no responde al tratamiento médico ${ }^{48}$.

\section{Agradecimientos}

Al Dr. M. Poza Poza, por su amable revisión de este artículo.

\section{Bibliografía}

1. Abboud, C.F., Laws, E.R.: Clinical endocrinological approach to hypothalamic-pituitary disease. J Neurosurg 1979; 51: 271-291.

2. Aihara, H., Tamaki, N., Ueyama, T., Ishihara, Y., Kondoh, T.: Transsphenoidal surgery for a case of empty sella syndrome associated with GH secreting pituitary adenoma. No Shinkei Geka 1996; 24:,1119-1123.

3. Albad,r F.B., Alorainy, I.A.: Radiological management of cerebrospinal fluid rhinorrhea. Neurosciences 2004; 9: 158164.

4. Ammar, A., Al-Sultan, A., Al Mulhim, F., Al Hassan, A.Y.: Empty sella syndrome: does it exist in children? J Neurosurg 1999; 91:,960-963.
5. Arrieta, F.J., Carrasco, M., Campos, J.M., et al.: Silla turca vacía con herniación intraselar del quiasma óptico. Rev Clin Esp 1991; 188: 295-297.

6. Bateman, N., Mason, J., Jones, N.S.: Use of fluorescein for detecting cerebrospinal fluid rhinorrhoea: A safe technique for intrathecal injection. ORL 1999; 61: 131-132.

7. Beattie, A.M., Trope, G.E.: Glaucomatous optic neuropathy and field loss in primary empty sella syndrome. Can J Ophthalmol 1991; 26: 377-382.

8. Becejac, B., Vizner, B., Berkovié, M., Gnjidié, Z., Vrkljan, M.: Neuroendocrinological Aspects of Primary Emty Sella. Coll Antropol 2002; 26 Suppl:159-164.

9. Biaconcini, G., Bragagni, G., Biaconcine, M.: Primary empty sella syndrome. Observations on 71 cases. Recenti Prog Med 1999; 90: 73-80.

10. Boluda Monzo, S., Mesa Manteca, J., Obiols Alfonso, G., Simo Canonge, R.: Cushing disease and primary empty sella turcica. Med Clin (Barc) 1989; 92: 396-397.

11. Brismar, K., Bergstrand, G.: CSF circulation in subjects with empty sella syndrome. Neuroradiology 1981; 21: 167-175.

12. Brismar, K.: Prolactin secretion in the Empty Sella Sindrome, in prolactinomas and in acromegaly. Acta Med Scand 1981; 209: 397-405.

13. Brodsky, M.C., Vaphiades, M.: Magnetic resonance imaging in pseudotumor cerebri. Ophthalmology 1998; 105: 1686-1693.

14. Buckman, M.T., Husain, M., Carlow, T.J., Peake, G.T.: Primary empty sella syndrome with visual field defects. Am J Med 1976; 61: 124-128.

15. Burgett, R.A., Purvin, V.A., Aki, K.: Lumboperitoneal shunting for pseudotumor cerebri. Neurology 1997; 49: 734739.

16. Busch, W.: Die Morphologie der sella turcica und ihre beziehungen zur Hipophyse. Arch. Pathol 1951; 320: 437458.

17. Cacciari, E., Zucchini, S., Ambrosetto, P. et al.: Empty sella in children and adolescents with possible hypothalamicpituitary disorders. J Clin Endocrinol Metab 1994; 78: 767771.

18. Cannavo, S., Curtó, L., Venturino, M., et al.: Abnormalties of hypothhalacmic.pituitary-thyroid axis in patients with primary empty sella. J Endocrinol Invest 2002; 25: 236239.

19. Chan, D.T., Poon, W.S., IP C.P., Chiu, P.W., Goh, K.Y.: How useful is glucose detection in diagnosing cerebrospinal fluid leak? The rational use of CT and Beta-2 transferrin assay in detection of cerebrospinal fluid fistula. Asian J Surg 2004; 27: 39-42.

20. Chandrasekaran, S., McCluskey, P., Minassian, D., Assaad, N.: Visual outcomes for optic nerve sheath fenestration in pseudotumour cerebri and related conditions. Clin Experiment Ophthalmol 2006; 34: 661-665. 
21. Cook, D.M.: Shouldn't adults with growth hormone deficiency bo offered grow hormone replacement therapy? Ann Intern Med 2002; 137: 197-201.

22. Costigan, D.C., Daneman, D., Harwood-Nash, D., Holland, F.J.: The "empty sella" in childhood. Clin Pediatr (Phila) 1984; 23: 437-440.

23. Cupps, T.R., Woolf, P.D.: Primary empty sella syndrome with panhypopituitarism, diabetes insipidus, and visual field defects. Acta Endocrinol (Copenh) 1978; 89: 445-460.

24. Davis, E., Kaye, A.H.: A dynamic pressure study of spontaneous CSF rhinorrhea in the empty sella syndrome. J Neurosurg 1980; 52: 103-105.

25. De Marinis, L., Bonadonna, S., Bianchi, A., Maria, G., Giustina, A.: Extensive clinical experience. Primary Empty Sella. J Clin Endocrinol Metab 2005; 90: 5471-5477.

26. Du Boulay, G.H.: Pulsatile movements in the CSF pathways. Br J Radiol 1966; 39: 255-262.

27. Du Boulay, G.H., El Gammal, T.: The cassificaction, clinical value and mechanism of sella turcica changes in raised ICP. Br J Radiol 1966; 39: 422-442.

28. Eljamel, M.S., Pidgeon, C.N.: Localization of inactive cerebrospinal fluid fistulas. J Neurosurg 1995; 83: 795-798.

29. Eljamel, M.S.M.: The role of surgery and beta2transferrin in the management of cerebrospinal fluid fistula [MD thesis]. Liverpool: University of Liverpool, 1993.

30. Estopinan, V., Fortea, L., Gracia, P., Baiges, J.J.: Primary empty sella turcica: clinical aspects and hormonal study of 15 cases. An Med Interna 1991; 8: 537-541.

31. Evans, D.G., Ladusans, E.J., Rimmer, S., Burnell, L.D., Thakker, N., Farndon, P.A.: Complications of the naevoid basal cell carcinoma syndrome: results of a population based study. J Med Genet 1993; 30: 460-464.

32. Findell, P.R., Mulchahey, J.J., Shepard, J.M. et al.: Direct measurement of blood pressure within the long hypophysial portal blood vessels. Neuroendocrinology 1987; 45: 263-266.

33. Foley, K.M., Posner, J.B.: Does pseudotumor cerebri cause the empty sella syndrome? Neurology 1975; 25: 565569.

34. Foresti, M., Guidali, A., Susanna, P.: Sella vuota primitive. Frequenza in 500 soggetti asintomática esaminati con Risonanza Magnetica. Radiol Med 1991; 81: 803-807.

35. Gallardo, E., Schachter, D., Caceres, E., et al.: The empty sella: results of treatment in 76 successive cases and high frequency of endocrine and neurological disturbances. Clin Endocrinol (Oxf) 1992; 37: 529-533.

36. Ganguly, A., Stanchfield, J.B., Roberts, T.S., et al.: Cushing's syndrome in a patient with an empty sella turcica and microadenoma of the adenohypophisis. AJM 1976; 60: 306-309.

37. García-Uría, J., Ley, L., Pajarón, A., Bravo, G.: Spontaneous cerebrospinal fluid fistulae associated with empty sellae: Surgical treatment and long-term results. Neurosurgery
1999; 45: 766-773.

38. Gasperi, M., Aimaretti, G., Cecconi, E. y col.: Impairment of GH secretion in adults with primary empty sella. J Endocrinol Invest 2002; 25: 329-333.

39. Gazioglu, N., Akar, Z., Ak, H., et al.: Extradural ballon obliteration of the empty sella. Report of trhee cases (intrasellar ballon obliteration). Acta Neurochir (Wien) 1999; 141: 487-494.

40. Gharib, H., Harald, M., Laws, E.R. et al.: Coexistent primary empty sella Syndrome and hyperprolactinemia. Arch Intern Med. 1983; 143: 1383-1386.

41. Gibby, W.A., Cohen, M.S., Goldberg, H.I., Sergott, R.C.: Pseudotumor cerebri: CT findings and correlation with vision loss. AJR Am J Roentgenol. 1993; 160: 143-146.

42. Gonzalez, J.G., Elizondo, G., Saldivar, D. et al.: Pituitary gland growth during normal pregnancy: an in vivo study using magnetic resonance imaging. Am J Med 1988; 85: 217 220.

43. Greenberb, M.S.: Idiopathic Intracranial Hypertension. En Mark S. Greenberg (ed). Handbook of Neurosurgery. Fifth edition. Stuttgart (Germany); Thieme International, 2001; pp: 471-474.

44. Guinto, G., del Valle, R., Nishimura, E. et al.: Primary empty sella syndrome: the role of visual system herniation. Surg Neurol. 2003; 60: 177-178.

45. Guiot, G.: An operation for symptomatic empty sella: Extradural packing of the sella turcica by transsphenoidal approach. Rev Esp Otoneurooftalmol Neurocirg 1973; 31: 97106.

46. Hadad, G., Bassagasteguy, L., Carrau, R.L., et al.: A novel reconstructive technique after endoscopic expanded endonasal approaches: Vascular pedicle nasoseptal flap. Laryngoscope 2006; 116: 1882-1886.

47. Hardy, J.: Closure of cerebrospinal fluid leakage after transsphenoidal surgery: Technical note. Neurosurgery 1994; 35: 1189.

48. Hashimoto, N., Okamoto, S., Yamagami, T., Kojima, M., Nakahara, I., Handa, H.: Treatment of primary empty sella with intractable headache via the transsphenoidal approach. No Shinkei Geka 1985; 13: 791-796.

49. Hegazy, H.M., Carrau, R.L., Snyderman, C.H. et al.: Transnasal Endoscopic Repair of Cerebrospinal Fluid Rhinorrhea. A Meta-Analysis.Laryngoscope 2000; 110:1 166-1172.

50. Ikeda, K., Nakano, M., Tnai, E.: Tension pneumocephalus complicating ventriculoperitoneal shunt for cerebrospinal fluid rhinorrhea: case report. J Neurol Neurosurg Psychiatry 1978; 41: 319-322.

51. Johnson, L.N., Krohel, G.B., Madsen, R.W., March, G.A. Jr.: The role of weight loss and acetazolamide in the treatment of idiopathic intracranial hypertension (pseudotumor cerebri). Ophthalmology. 1998; 105: 2313-2327.

52. Jordan, R.M., Kendall, J.W., Kerber, C.W.: The primary empty sella syndrome: analysis of the clinical characteristics, 
radiographic features, pituitary function and cerebrospinal fluid adenohypophysial hormone concentrations. Am J Med 1977; 62: 569-580.

53. Karahalios, D.G., Rekate, H.L., Khayata, M.H., Apostolides, P.J.: Elevated intracranial venous pressure as a universal mechanism in pseudotumor cerebri of varying etiologies. Neurology 1996; 46: 198-202.

54. Kaufman, B., Tomsak, R.L., Kaufman, B.A. et al.: Herniation of the suprasellar visual system and third ventricule into empty sellae: Morphologic and clinical considerations. AJR 1989; 152: 597-608.

55. Kaufman, B.: The "empty" sella turcica. A manifestation of the intrasellar suarachnoid space. Radiology 1968; 90 : 931-941.

56. Kelestimur, F.: Sheehan's Syndrome. Pituitary 2003; 6: $181-188$.

57. Kubo, S., Hasegawa, H., Inui, T., Tominaga, S., Yoshimine, T.: Endonasal endoscopic transsphenoidal chiasmapexy with silicone plates for empty sella syndrome. Neurol Med Chir (Tokyo) 2005; 45: 428-432.

58. Landreneau, F.E., Bruce, M., Caetano, C..: Surgical treatment of cerebrospinal fluid fistulae involving lateral extension of the sphenoid sinus. Neurosurgery 1998; 42: 11011104.

59. Laws, E.R.: Commentary on "Endonasal endoscopic transsphenoidal chiasmapexy with silicone plates for empty sella syndrome -Technical note-" Neurol Med Chir (Tokyo) 2005; 45: 428-432.

60. Lee, T.C., Yang, L.C., Huang, P.L.: Treatment of empty sella syndrome with ventriculoperitoneal shunt. J Clin Neurosci 2005; 12: 201-205.

61. Leutenegger, M., Gross, A., Hublot, C.: Cushing's disease with corticotropic microadenoma and empty sella turcica. Nouv Presse Med 1982; 11: 454-455.

62. Levantin, P., Oakland, C.: Incresed intracranial pressure withaut papilledema. A.M.A. Archives of ophthalmology 1957; 58: 683-688.

63. Lim, M., Kurian, M., Penn, A. et al.: Visual failure without headache in idiopathic intracranial hypertension. Arch Dis Child 2005; 90: 206-210.

64. Locatelli, D., Rampa, F., Acchiardi, I. et al.: Endoscopic endonasal approaches for repair of cerebrospinal fluid leaks: nine-year experience. Neurosurgery 2006; 58 (4 Suppl 2): 246-256.

65. Maira, G., Anile, C., Mangiola, A.: Primary empty sella syndrome in a series of 142 patients. J Neurosurg 2005; 103: 831-836.

66. Maira, G., Anile, C., De Marinis, L., Mancini, A., Barbarino, A.: Cerebrospinal fluid pressure an prolactin in empty sella syndrome. Can J Neurol Sci 1990; 17: 92-94.

67. Majeed, P.A., Saini, J.S., Dash, R.J.: Co-existing prolactinoma with primary empty sella. J Assoc Physicians India $1985 ; 33: 241-243$.
68. Manelfe, C., Cellerier, P., Sobel, D. Prevost, C., Bonafé, A..: Cerebrospinal fluid Rhinorrhea. Evaluation with Metrizamide Cisternography. AJR 1982; 138: 471-476.

69. Marcelis, J., Silberstein, S.D.: Idiopathic intracranial hypertension without papilledema. Arch Neurol 1992; 49:14.

70. Mokri, B.: Intracranial hypertension after treatment of spontaneous cerebrospinal fluid leaks. Mayo Clin Proc 2002; 77: 1241-1246.

71. Monnet, F., Elias, K.A., Fagin, K., Neill, A., Goldsmith, P., Weiner, R.I.: Formation of a direct arterial blood supply to the anterior pituitary gland following complete or partial interruption of the hypophyseal portal vessels. Neuroendocrinology 1984; 39: 251-255.

72. Mortara, R., Norell, H.: Consequences of a deficient sellar diaphragm. J Neurosurg 1970; 32: 565.

73. Nagao, S., Kinugasa, K., Nishimoto, A.: Obliteration of the primary empty sella by transsphenoidal extradural ballon inflation: Tecnical note. Surg Neurol 1987; 27: 455-458.

74. Page, R.B., Bergland, R.M.: Pituitary vasculature. En Allen M.B. Jr., Mahesh V.B. (ed): The Pituitary: a Current Review. New York; Academic Press, 1977, pp 9-17.

75. Peter, J.S., Heinz, E.R.: The sella turcica in multiparity; with comments on the effects of pseudotumor cerebri. British Journal of Radiology 1972; 45: 503-506.

76. Pocecco, M., de Campo, C., Marinoni, S., et al.: High frequency of empty sella syndrome in children with growth hormone deficiency. Helv Paediatr Acta. 1989; 43: 295-301.

77. Polyzoidis, K.S., Fylaktakis, M.: Transsphenoidal extradural chiasmapexy in the management of the symptomatic primary empty sella syndrome. Zentralbl Neurochir 1993; 54: $128-132$.

78. Prichard, C.N., Isaacson, B., Oghalai, J.S., Coker, N.J., Vrabec, J.T.: Adult spontaneous CSF otorrhea. Correlation with radiographic empty sella. Otolaryngology-Head and Neck Surgery 2006; 134: 767-771.

79. Risch, L., Lisec, I., Jutzi, M. et al.: Rapid, accurate and non-invasive detection of cerebrospinal fluid leakage using combined determination of beta-trace protein in secretion and serum. Clin Chim Acta 2005; 351: 169-176.

80. Schaeffer, J.P.: Some poits in the regional anatomy of the optic pathway with special refernce to tumors of the hipophysis cerebri and resulting ocular changes.Anat. Rec 1924; 28: 243-279.

81. Schlosser, R.J., Bolger, W.E.: Significance of empty sella in cerebrospinal fluid leaks. Otolaryngol Head Neck Surg. 2003; 128: 32-38.

82. Schlosser, R.J., Bolger, W.E.: Spontaneus nasal cerebrospinal fluid leaks and empty sella syndrome: a clinical presentation. Am J Rhinol 2003; 17: 91-96.

83. Schmerber, S., Righini, Ch., Lavielle, J-P., et al.: Endonasal Endoscopic Closure of Cerebrospinal Fluid Rhinorrhea.Skull Base 2001; 11: 47-58.

84. Shetty, P.G., Shroff, M.M., Fatterpekar, G.M. et al.: A 
Retrospective Analysis of Spontaneous Sphenoid Sinus Fistula: MR and CT Findings.AJNR Am J Neuroradiol 2000; 21: 337-342.

85. Shinoda, Y., Ohnishi, Y., Abe, M., et al.: Empty sella syndrome with visual field disturbance. Jpn J Ophthalmol 1983; 27: 248-254.

86. Silbergleit, R., Junck, L., Gebarski, S.S., Hatfield, M.K.: Idiopathic intracranial hypertension (pseudotumor cerebri): MR imaging. Radiology 1989; 170: 207-209.

87. Sismanis, A., Butts, F., Hughes, G.B.: Objective Tinnitus in Benign Intracranial Hypertension: An Update. Laryngoscope 1990; 100: 33-36.

88. Smaltino, F., Bernini, F.P., Muras, I.: Computed tomography for diagnosis of empty sella associated with enhancing pituitary microadenoma. J Comput Assist Tomogr. 1980; 4: 592-599.

89. Soliman, A.T., Darwish, A., Asfour, M.G.: Empty sella in short children with and without hypothalamic-pituitary abnormalities. Indian J Pediatr 1995; 62: 597-603.

90. Spaziante, R., Divitiis, E., Stella, L., et al.: The empty sella. Surgical Neurol 1981; 16: 418-426.

91. Strömberg, S., Crock, P., Lernmark, A., Hulting, A.L.: Pituitary autoantibodies in patients with hypopituitarism and ther realtives. Journal of Endocrinology 1998; 157: 475-480.

92. Sugerman, H.J., DeMaria, E.J., Felton, W.L. $3^{\text {rd }}$, et al.: Increased intra-abdominal pressure and cardiac filling pressures in obesity-associated pseudotumor cerebri. Neurolgy 1997; 49: 507-511.

93. Sugerman, H.J., Felton, W.L. $3^{\text {rd }}$., Sismanis, A., et al.: L. Gastric surgery for pseudotumor cerebri associated with severe obesity. Ann Surg 1999; 229: 634-40; discussion 640642 .

94. Sureda, B., Alberca, R.: Benign intracranial hypertension and obesity. Neurologia. 1990; 5: 260-264.

95. Sutton, T.J., Vezina, J.L.: Co-existing pituitary adenoma and intrasellar arachnoid invagination. Amer J Roendgen 1974; 122: 508-510.

96. Swanson, J.A., Sherman, B.M., Van Gilder, J.C., Chapler, F.K.: Coexistent empty sella and prolactin-secreting microadenoma.. Obstet Gynecol 1979; 53: 258-263.

97. Syed, B.A.: Nontraumatic (spontaneous) cerebrospinal fluid rhinorrhea from cribriform fistula associated with primary empty sella: report of two cases and literature review. Annals of Saudi Medicine 2000; 20: 43-46.

98. Takanashi, J., Suzuki, H., Nagasawa, K et al.: Empty sella in children as a key for diagnosis. Brain Dev 2001; 23 : 422-423.

99. Tosun, F., Carrau, R.L., Snyderman, C.H., et al.: Endonasal endoscopic repair of cerebrspinal fluid leaks of the sphenoid sinus. Arch Otolaryngol Head Neck Surg 2003; 129 : 576-580.
100. Vazquez, G., Alger ,M., Cabrera, V.L., et al.: Evolución de la deficiencia hipofisaria después de corrección quirúrgica del síndrome de silla turca vacía. Rev Invest Clin (Mex) 1981; 33: 205-208.

101. Weisberg, L.A.: Computed tomography in benign intracranial hypertension. Neurology 1985; 35: 1075-1078.

102. Weiss, M.H., Kaufman, B., Richards, D.E.: Cerebrospinal fluid rhinorrea from an empty sella: Transsphenoidal obliteration of the fistula. Technical note. J Nerosurg 1973; 39: 674-676.

103. Wessel, K., Thron, A., Linden, D., Petersen, D., Dichgans, J.: Pseudotumor cerebri: clinical and neuroradiological findings. Eur Arch Psychiatry Neurol Sci 1987; 237: 54-60.

104. Wolf, G., Greistorfer, K., Stammberger, H..: Endoscopic detection of cerebrospinal fluid fistulas with a fluorescence technique. Report of experiences with over 925 cases. Laryngorhinootologie 1997; 76: 588-594.

105. Wood, J.G., Dogali, M.: Visual improvement after chiasmapexy for primary empty sella turcica. Surg Neurol 1975; 3: 291-294.

106. Wraige, E., Chandler, C., Pohl, K.R.E.: Idiopathic intracranial hypertension: is papilloedema inevitable? Arch Dis Child 2002; 87: 223-224.

107. Xuereb, G.P., Prichard, M.M., Daniel, P.M.: The arterial supply and venous drainage of the human hypophysis cerebri. Q J Exp Physiol Cogn Med Sci 1954; 39: 199217.

108. Yuh, W.T., Zhu, M., Taoka, T. et al.: MR imaging of pituitary morphology in idiopathic intracranial hypertensinon. J Magn Reson Imaging 2000; 12: 808-813.

109. Zagardo, M.T., Cail, W.S., Kelman, S.E., Rothman, M.I.: Reversible empty sella un idiopathic intracranial hipertensión: an indicador of successful therapy? AJNR 1996; 17: 1953-1956.

110. Zona, G., Testa, V., Sbaffi, P.F., Spaziante, R.: Transsphenoidal treatment of empty sella by means of a silastic coil: Technical note. Neurosurgery 2002; 51: 1299-1303.

111. Zucchini, S., Ambrosetto, P., Carla, G., Tani, G., Franzoni, E., Cacciari, E.: Primary empty sella: differences and similarities between children and adults. Acta Paediatr 1995; 84: 1382-1385.

112. Zuckerman, J., Stankiewicz, J.A., Chow, J.M.: Longterm outcomes of endoscopic repair of cerebrospinal fluid leaks and meningoencephaloceles. Am J Rhinol 2005; 19: 582-587.

González-Tortosa, J.: Silla Turca vacía primaria: clínica, fisiopatología y tratamiento. Neurocirugía 2009; 20: 132-151.

Correspondencia con el autor: tortosa@ctv.es 